\title{
Complex, multi-layered azimuthal anisotropy beneath Tibet: Evidence for co-existing channel flow and pure-shear crustal thickening
}

\author{
Matthew R. Agius ${ }^{1,}{ }^{\star}$ and Sergei Lebedev ${ }^{1}$ \\ ${ }^{1}$ Geophysics Section, Dublin Institute for Advanced Studies, 5 Merrion Square, Dublin, Ireland.
}

\section{SUMMARY}

Of the two debated, end-member models for the late-Cenozoic thickening of Tibetan crust, one invokes "channel flow" (rapid viscous flow of the mid-lower crust, driven by topography-induced pressure gradients and transporting crustal rocks eastward) and the other- "pure shear" (faulting and folding in the upper crust, with viscous shortening in the mid-lower crust). Deep-crustal deformation implied by each model is different and would produce different anisotropic rock fabric. Observations of seismic anisotropy can thus offer a discriminant. We use broadband phase-velocity curves-each a robust average of tens to hundreds of measurements-to determine azimuthal anisotropy in the entire lithosphere-asthenosphere depth range and constrain its amplitude. Inversions of the differential dispersion from path pairs, region-average inversions and phase-velocity tomography yield mutually consistent results, defining two highly anisotropic layers with different fast-propagation directions within each: the middle crust and the asthenosphere. In the asthenosphere beneath central and eastern Tibet, anisotropy is 2-4 per cent and has a NNE-SSW fast-propagation azimuth, indicating flow probably driven by the NNEward, shallow-angle subduction of India. The distribution and complexity of published shear-wave splitting measurements can be accounted for by the different anisotropy in the mid-lower crust and asthenosphere. The estimated splitting times that would be ac- 
cumulated in the crust alone are $0.25-0.8 \mathrm{~s}$; in the upper mantle-0.5-1.2 s, depending on location. In the middle crust (20-45 km depth) beneath southern and central Tibet, azimuthal anisotropy is 3-5 and 4-6 per cent, respectively, and its E-W fast-propagation directions are parallel to the current extension at the surface. The rate of the extension is relatively low, however, whereas the large radial anisotropy observed in the middle crust requires strong alignment of mica crystals, implying large finite strain and consistent with high-rate horizontal flow. Together, radial and azimuthal anisotropy suggest eastward mid-crustal channel flow in central Tibet, along the regional topography gradient. In NE high Tibet, mid-crustal azimuthal anisotropy is $4-8$ per cent and has WNW-ESE and NW-SE fast-propagation directions, parallel to the net extension at the surface. These fast directions are inconsistent with channel flow following the SW-NE regional topography gradient. Instead, they suggest similar net deformation in the (decoupled) shallow and deep crust. In the brittle upper crust, it is accommodated by strike-slip faulting; in the ductile mid-lower crust-by shear oriented at $\sim 45^{\circ}$ to the faults. Although mid-crustal flow beneath NE Tibet may transport some material towards the plateau periphery at a low region-average rate, the dominant mid-crust deformation pattern is shear parallel to the plateau boundary. This implies that channel flow from central Tibet is not the main cause of the on-going crustal thickening farther northeast.

Key words: Asia - Surface waves and free oscillations - Seismic interferometry - Seismic anisotropy - Dynamics of lithosphere and mantle

\section{INTRODUCTION}

In the course of India's ongoing collision with Asia, the Tibetan Plateau has undergone substantial north-south shortening (e.g., Yin \& Harrison 2000). Most of the crustal thickening associated with the shortening has occurred within the boundaries of the plateau set prior to the collision by lithospheric strength contrasts (weaker lithosphere beneath what is now Tibet and stronger lithosphere beneath the surrounding Tarim, Qaidam and Sichuan Basins (e.g., Yuan et al. 2013) (Fig. 1). Within these

* Now at: National Oceanography Centre Southampton, University of Southampton Waterfront Campus, European Way, Southampton, United Kingdom. 
boundaries, the crust thickened progressively. The highest terrane in the western, central and southern parts of Tibet, where the surface elevation may now have reached a maximum ( $>5.5 \mathrm{~km}$, Fig. $2 \mathrm{a})$, continues to expand towards the north and east of the plateau. The mechanisms of the growth of the high plateau and the associated thickening of the crust are at the heart of the models of the plateau evolution. Yet, after decades-long debate, they remain uncertain.

Two end-member mechanisms for the thickening of Tibetan crust can be referred to as "pure shear" and "channel flow" (e.g., Lease et al. 2012). The former invokes crustal thickening by means of faulting and folding in the upper crust ( $\lesssim 20 \mathrm{~km}$ depth) and lateral shortening in the mid-lower crust ( $20 \mathrm{~km}$ depth to Moho) (e.g., Hubbard \& Shaw 2009). The latter invokes horizontal viscous flow in the mid-lower crust, transporting large volumes of crustal rocks into the eastern, southeastern and northeastern Tibet and thus inflating the crust there; this mechanism does not require significant shortening of the upper crust (Royden et al. 1997; Clark \& Royden 2000).

Both end-member mechanisms may have been at work. For northeastern and eastern Tibet, recently constructed shortening budgets and other geological evidence suggest that pure shear alone could account for the Cenozoic crustal thickening (e.g., Hubbard \& Shaw 2009; Lease et al. 2012; Wang et al. 2012). For southeastern Tibet, the apparent lack of evidence for significant shortening is consistent with crustal thickening by deep crustal flow (Royden et al. 2008).

Global Positioning Systems (GPS) measurements show surface velocity vectors aligning northnortheast at stations in central Tibet and undergoing a smooth, clockwise rotation round the eastern Himalayan syntaxis (e.g., Wang et al. 2001; Zhang et al. 2004). The geodetic measurements and earthquake fault-plane solutions show clearly that the highest—western and central—parts of the plateau now undergo extension, the northern and eastern parts—strike-slip deformation, and the northeastern periphery of the plateau — compression (e.g., Shapiro et al. 2004; Copley et al. 2011; Agius \& Lebedev 2014; Ge et al. 2015) (Fig. 2). It is less clear what the deformation is below the upper crust, within the deep crust and upper mantle.

Specifically, one key question is whether the net deformation of the mid-lower crust is similar to that of the upper crust (deformation in the two being either coupled or co-incident) or if, instead, the deformation and flow of the lower crust are different from the upper-crustal deformation (channel flow). Based on geophysical evidence, there is little doubt that mid-lower crust beneath vast areas of Tibet is partially molten, has low viscosity, and can accommodate viscous flow (e.g., Nelson et al. 1996; Yang et al. 2012; Agius \& Lebedev 2014), but what the actual patterns of lower-crustal deformation are remains an open question.

A record of deformation at depth can be obtained from the strain-induced anisotropy in crustal and mantle rocks. Studies of shear-wave splitting (birefringence of shear waves) have detected substantial 
seismic anisotropy beneath Tibet. Fig. 1 shows a compilation of the shear-wave splitting measurements in and around Tibet (McNamara et al. 1994; Hirn et al. 1995; Sandvol et al. 1997; Huang et al. 2000; Herquel \& Tapponnier 2005; Lev et al. 2006; Singh et al. 2006, 2007; Sol et al. 2007; Fu et al. 2008; Kumar \& Singh 2008; Wang et al. 2008; Chen et al. 2010; Zhao et al. 2010; Huang et al. 2011; Leon Soto et al. 2012). The shear-wave birefringence is evidence of anisotropic fabric of the rocks at depth, created by finite strain within the continental crust, mantle lithosphere and the underlying asthenosphere. The distribution of the fast-propagation directions shows clear regional trends, with the fast azimuths primarily between E-W and NE-SW in the western and central parts of the plateau, primarily between WSW-ENE and WNW-ESE in the northeastern part, and rotating clockwise around the east Himalayan syntaxis in the southeastern part, from E-W and SE-NW to the west of the syntaxis to NW-SE and then N-S to the east of the syntaxis. A detailed examination reveals that, in many locations, measurements from stations close to one another show different fast directions and splitting times, the latter ranging from null to $>2$ seconds. The origins of these apparent inconsistencies in different parts of the plateau have been debated, attributed to differences in data sampling in different studies, structural heterogeneity beneath Tibet and the presence of multiple layers of anisotropy (e.g., Gao \& Liu 2009; Chen et al. 2010).

Surface waves provide depth resolution of seismic-velocity structure and anisotropy in the entire lithosphere-asthenosphere depth range. Depth-dependent azimuthal anisotropy beneath Tibet has been reported in a number of Rayleigh-wave and multimode Rayleigh-wave studies (Huang et al. 2004; Su et al. 2008; Yao et al. 2010; Yi et al. 2010; Pandey et al. 2015; Xie et al. 2016; Schaeffer et al. 2016), although anisotropy properties inferred in different studies have displayed substantial differences. The amplitude of anisotropy, in particular, is difficult to constrain in large tomographic inversions and remains uncertain.

Accurate estimates of the amplitude of both azimuthal and radial anisotropy in different parts of Tibet are required in order to relate anisotropy to deformation at depth (e.g., Shapiro et al. 2004; Xie et al. 2016). In a recent study (Agius \& Lebedev 2014), we measured the amplitudes of radial anisotropy using Rayleigh and Love-wave dispersion curves across Tibet. The purpose of the present study is to determine the depth-dependent azimuthal anisotropy beneath Tibet and to put tight constraints on its amplitude. We use a few tens of specially selected, broadband, accurate interstation phase-velocity curves for Rayleigh waves and apply a number of complementary surface-wave analysis approaches, including differential dispersion analysis. In the following, we present, one by one, the applications of each technique and the corresponding results-all mutually consistent and leading to the same inferences and conclusions regarding the distributions of anisotropy and the mechanisms of deformation of the crust and upper mantle beneath Tibet. 


\section{MEASUREMENTS}

Today's large-scale regional and global tomography studies constrain distributions of azimuthal seismic anisotropy using as many as tens or hundreds of thousands of source-station or station-station paths. A number of such tomographic models were focussed on Tibet or presented with a spotlight on the India-Asia collision zone (Priestley et al. 2006; Yang et al. 2010a; Pandey et al. 2015; Schaeffer et al. 2016). In this study, in contrast, we aim to constrain azimuthal anisotropy beneath Tibet more accurately than previously by using only a few tens of interstation dispersion curves (even though each interstation curve is determined from tens to hundreds of single-event dispersion curves).

The advantage of the interstation, phase-velocity measurements is that they are made in broad period ranges, from periods as short as a few seconds to periods well over 100 seconds. Combining the short and long period data enables us to resolve the structure and anisotropy in both the crust and upper mantle and to reduce the substantial trade-offs between parameters in the different depth ranges. Also, the small size of the inverse problems relating interstation dispersion curves to shear-velocity anisotropy models enables us to constrain the anisotropy beneath selected locations within Tibet more accurately than large tomographic models, which are very useful in mapping anisotropy across entire regions but in which it is difficult to quantify uncertainty, with anisotropy and its amplitude being particularly uncertain (as illustrated by Schaeffer et al. (2016) for the current generation of global models).

In this study we complement the data used in Agius \& Lebedev $(2013,2014)$ with new dispersion measurements for northeastern Tibet (primarily within the Songpan-Ganzi block), south-east Tibet (across the Yunnan Province), round the eastern syntaxis, and a few more east-west paths across central Tibet (Fig. 3). Each station pair was chosen so that numerous suitable earthquake recordings were available for the measurements of interstation surface-wave dispersion, resulting in robust average phase-velocity curves.

\subsection{Interstation measurements}

We use a recent implementation of the classical two-station method to measure phase velocities of the fundamental-mode Rayleigh waves (Meier et al. 2004; Lebedev et al. 2006). The method comprises two different techniques, so as to yield phase velocities in the broadest possible period ranges: cross correlation of pairs of seismograms (Meier et al. 2004) and derivation of phase velocities from sourcestation measurements, obtained with multi-mode waveform fitting (Lebedev et al. 2005, 2006).

In the cross-correlation method, the vertical component seismograms of an earthquake recorded at two stations with nearly the same back azimuth towards the event (10 degree maximum difference) are cross correlated. Frequency-dependent band-pass Gaussian filters and frequency-dependent time 
windows are applied to the cross-correlation function to enhance the signal-to-noise ratio and reduce side lobe energy resulting from correlations of the fundamental mode with higher modes or scattered waves. The Rayleigh-wave phase velocities are then computed from the phase of the cross-correlation function and the difference between the distances from the event to each of the stations. Smooth portions of dispersion curves of the fundamental mode are selected manually; numerous single-event measurements are averaged together to yield a robust phase-velocity curve for the station pair (Meier et al. 2004; Agius \& Lebedev 2013, 2014). We verify that measurements made from earthquakes in different source regions and on the opposite sides of the interstation paths are consistent. The elaborate signal treatment introduced by Meier et al. (2004) (see also the more detailed description of the signal processing in Soomro et al. (2016)) has made possible cross-correlation measurements of phase velocities at periods much shorter than with other implementations of the method.

Long-period surface waves can interfere with energetic body waves (which can be thought of, alternatively, as superposition of surface-wave higher modes). The interference will preclude accurate measurements using cross correlation. In this case, phase velocities can, instead, be measured using full waveform fitting. We use the Automated Multimode Inversion (AMI) by Lebedev et al. (2005) to simultaneously fit S, multiple S, and surface waves. From successful waveform fits of the recordings of the same event at two stations (again, approximately on the same great circle with the event), we extract the source-station, fundamental-mode dispersion curves and compute interstation phase velocities.

The measurements yielded by the two methods are complementary and consistent where they overlap (Lebedev et al. 2006; Agius \& Lebedev 2013). The cross-correlation method produces most of the measurements; AMI contributes primarily long- and intermediate-period measurements. All the single-event dispersion curves are reselected manually; outlier or rough (not smooth) curves or curve portions are removed. More details on the methods and examples of how hundreds of consistent, combined AMI and cross-correlation measurements yield broadband, smooth dispersion curves can be found in Agius (2013) and Agius \& Lebedev (2013, 2014).

In total, our combined data set includes 56 station pairs distributed across the Tibetan Plateau. The broadband stations belonged to temporary networks that operated at different times (PASSCAL (1991-1992) (Owens et al. 1993), INDEPTH II (1994) (Nelson et al. 1996), INDEPTH III (19971999) (Huang et al. 2000), PASSCAL (Lehigh, 2003-2004) (Sol et al. 2007), PASSCAL (MIT, 20032004) (Lev et al. 2006), and HI-CLIMB (2004-2005) (Nábělek et al. 2005)) and to the permanent China Digital Seismic Network. Fig. 3 shows the station locations. Interstation lines indicate the station pairs used to obtain the dispersion measurements plotted on the adjacent graph. At intermediate periods, between 20 and 40 seconds, paths sampling outside high elevation areas (Qinling-Qilian, Sichuan Basin) show higher phase velocities than the paths sampling the high Tibetan Plateau, where 
the crust is thicker. Yunnan, which has a smoothly changing elevation, shows intermediate phase velocities. At short periods $(<20 \mathrm{~s})$, dispersion curves show strong variability, indicating significant heterogeneity in the shallow crust, particularly in southern Tibet (close to the Himalayas) and near the eastern Himalayan syntaxis.

\subsection{Rayleigh-wave dispersion across Tibet}

Lateral phase-velocity variations at different periods reflect structural heterogeneity within the crust and mantle across the plateau (Fig. 4). At $25 \mathrm{~s}$, phase velocities for different station pairs in central Tibet are very similar, indicating a relatively homogeneous structure. Velocities increase gradually towards South Yunnan, in contrast to an abrupt change across the Kunlun Fault or between the plateau and the Sichuan Basin. These increases in phase velocity are primarily due to the crust becoming thinner and, to a lesser extent, to increases in crustal seismic velocities (Agius \& Lebedev 2014). Upon closer inspection, west-east aligned station pairs in central Tibet show higher velocities than the north-south aligned pairs - an effect of azimuthal anisotropy, as we explore further below. Higher velocities can also be seen for northwest-southeast oriented paths in Songpan-Ganzi.

At longer periods, high phase velocities in western Lhasa indicate the cold lithosphere of India, underthrust beneath the Tibetan crust, whereas the low phase velocities in northern Tibet indicate much warmer Tibetan shallow upper mantle (Barazangi \& Ni 1982; Agius \& Lebedev 2013). At $80 \mathrm{~s}$ period, phase velocities of adjacent paths within east-central Tibet differ significantly as a function of azimuth, an indication of anisotropy in the upper mantle.

The frequency-dependent depth sensitivity of the phase velocities is illustrated in Fig. 5. At 25 and $50 \mathrm{~s}$, Rayleigh waves have peak sensitivity within the middle and lower crust, respectively. At longer periods ( 80 s), Rayleigh waves are sensitive primarily to mantle structure.

\section{AZIMUTHAL ANISOTROPY}

Finite shear strain in crustal rocks causes anisotropic mineral crystals such as micas (Weiss et al. 1999; Nishizawa \& Yoshino 2001; Meltzer \& Christensen 2001) and amphiboles (Barruol \& Kern 1996; Tatham et al. 2008) to develop a preferred orientation. In the upper mantle, the dominant mineral olivine also develops a lattice preferred orientation, parallel to the flow direction (Zhang \& Karato 1995). The resulting intrinsic anisotropy can be detected seismically, from the azimuthal and polarization dependence of wave speeds. Hence, anisotropy yields information on deformation. Here, we estimate the azimuth, amplitude, and depth range of anisotropic layers beneath Tibet using the broad- 
band, phase-velocity curves. A suite of alternative approaches for the inversion and analysis of the curves all yield mutually consistent results.

\subsection{Phase-velocity maps}

Regional azimuthal anisotropy can be mapped by a tomographic inversion for both isotropic-average and azimuthally anisotropic variations (e.g., Deschamps et al. 2008; Darbyshire \& Lebedev 2009). We start with anisotropic phase-velocity tomography at a range of periods (Fig. 6). We recognize that our dataset comprises a relatively small number of (highly accurate) measurements, and its strength is not in providing a dense path coverage of the entire area (the coverage is, indeed, sparse) but in constraining the amplitude of anisotropy, as described in the following sections. The purpose of these tomographic inversions is thus to examine the dominant, region-scale patterns of anisotropy. Importantly, our inversions reveal the same dominant regional anisotropy patterns as recent tomography with some of the largest datasets to date (Yang et al. 2010b; Shen et al. 2016), confirming that our data samples these patterns accurately.

At a frequency $\omega$ and propagation azimuth $\psi$, the phase-velocity anomaly $\delta C(\omega)$ comprises isotropic $\left(\delta C_{i s o}(\omega)\right)$ and anisotropic terms:

$$
\begin{aligned}
\delta C(\omega)=\delta C_{\text {iso }}(\omega) & +A_{1}(\omega) \cos 2 \psi+A_{2}(\omega) \sin 2 \psi \\
& +A_{3}(\omega) \cos 4 \psi+A_{4}(\omega) \sin 4 \psi
\end{aligned}
$$

Azimuthal variations are represented by the $2 \psi$ and $4 \psi$ terms to fit the $\pi$ and $\frac{\pi}{2}$ periodic variations, respectively (Smith \& Dahlen 1973). In the tomographic inversions, we solve, at each period, for an anisotropic phase-velocity map using the LSQR method (an algorithm for Sparse Linear Equations and Sparse Least Squares (Paige \& Saunders 1982)) with lateral smoothing and slight norm damping (Lebedev \& van der Hilst 2008; Deschamps et al. 2008; Zhang et al. 2009). The phase-velocity maps are intrinsically smooth to begin with, given the sparse, $\sim 300 \mathrm{~km}$ knot spacing of the triangular grid that they are parameterized on.

The $25 \mathrm{~s}$ map (Fig. 6) shows low isotropic-average phase velocities (pink shade) beneath the highelevation plateau, underlain by the thickest crust. High velocities (blue shade) appear beneath lowerelevation regions, underlain by thinner crust, as we have already seen in the interstation phase-velocity map in Fig. 4. At 50 and 80 s, high-velocity anomalies in southern Tibet indicate the subducting Indian plate. The isotropic-average and radially anisotropic structure of the Tibetan crust as constrained by broadband dispersion measurements has been discussed in detail by Agius \& Lebedev (2014), and the subduction of the Indian lithosphere beneath Tibet by Agius \& Lebedev (2013). Here, our focus is on azimuthal anisotropy (yellow sticks: the $(2 \psi)$ fast-propagation directions). 
In order to test the robustness of the models we ran a series of test inversions using different grid spacing and regularization and also with some data excluded (the removal of outliers, the measurements that were fit the worst by the tomographic models). Solutions from the test inversions consistently showed the same dominant isotropic and $2 \psi$ anisotropic patterns.

At 25 and 50 s periods, sampling the middle and lower crust, the preferred fast-propagation orientation is E-W for western and central Tibet and NW-SE in northeastern Tibet. At 80 s, east-central Tibet shows a SSW-NNE orientation for faster propagation. These patterns of azimuthal anisotropy at each period could already be seen in the distribution of relatively fast and slow interstation paths in the same locations (Fig. 4).

The anisotropy we see for the Tibetan mid-lower crust is so spatially coherent that it can be imaged clearly even by today's global anisotropic tomography (Schaeffer et al. 2016, with the 50,150 and $200 \mathrm{~km}$ map views of the smoother version of the global anisotropy model published previously in Becker et al. $(2014,2015)$ )—which confirms the pattern we see in Fig. 6. The same dominant pattern for the crust (E-W fast directions in central Tibet, NW-SE fast directions in northeastern Tibet) was imaged in the regional studies of Yang et al. (2010b) and Shen et al. (2016), who used very large regional datasets of interstation, surface-wave measurements obtained using ambient noise cross-correlations.

\subsection{Region-average azimuthal anisotropy}

In an alternative approach, we inverted phase velocities from all single-event measurements within northeastern Tibet for the orientation and amplitude of azimuthal anisotropy within this sub-region, assuming that the structure within it is, approximately, laterally homogeneous (Adam \& Lebedev 2012). Regional tomography (e.g., Yang et al. 2012; Shen et al. 2016, this study) shows a relatively homogeneous region here, supporting this assumption, even though some heterogeneity is certain to be present. The inversions use all single-event dispersion measurements from the station pairs within northeastern Tibet (Fig. 7, inset maps). For each station pair, the measurements are for events with back-azimuths distributed within a $20^{\circ}$ azimuthal window $\left( \pm 10^{\circ}\right.$ from the interstation great circle path), resulting in sufficient azimuthal coverage for unambiguous retrieval of anisotropy (Fig. 7). The data set, which comprises tens to hundreds of measurements from each station pair, is sorted by azimuth, weighted, and averaged using a $15^{\circ}$ sliding window, in order to remove potential biases due to uneven azimuthal sampling (Adam \& Lebedev 2012). At each period, alternative inversions are performed, one for $2 \psi$ anisotropy terms only and another for both $2 \psi$ and $4 \psi$ terms.

The results show two distinct anisotropy patterns (Fig. 7). At shorter periods up to $50 \mathrm{~s}$, the fastpropagation azimuth is NW-SE. It changes to SSW-NNE between 50 and 60 seconds and maintains 
this orientation for periods up to and over 100 seconds. The fast propagation azimuths given by the two sets of inversions ( $2 \psi$ only and both $2 \psi$ and $4 \psi$ ) are nearly identical. The amplitudes of anisotropy, however, differ (by $\lesssim 1$ per cent).

\subsection{Measurement of azimuthal anisotropy using differential dispersion}

The dominant region-scale anisotropy patterns that we see in the phase-velocity maps in Fig. 6 (the periods sampling mid-lower crust: E-W fast directions in central Tibet, NW-SE fast directions in northeastern Tibet; the periods sampling upper mantle: SSW-NNE fast direction in northeastern Tibet) are confirmed by the region-average inversions for the NE Tibet (Fig. 7) and also by recent regional and global tomography (Yang et al. 2010b; Becker et al. 2014, 2015; Schaeffer et al. 2016), indicating that the large-scale patterns of fast-propagation directions are robust. The same cannot be said of the amplitude: in tomographic inversions, anisotropy amplitude is difficult to recover completely and often depends on inversion regularization (Schaeffer et al. 2016). Our phase-velocity tomography (Fig. 6), for example, shows smaller anisotropy compared to the region-average inversion (Fig. 7), which, in turn, shows some dependence of the anisotropy amplitude on whether or not the $4 \psi$ terms are included.

In order to recover the amplitude of phase-velocity anisotropy, we now apply a simple new method using differential dispersion in our interstation measurements (Figs 8 and 9). If, in a given period range, the fast propagation azimuth of surface-wave anisotropy in a structural block is known, and if we have a pair of approximately perpendicular interstation paths within this structural block, one along the fastand another along the slow-propagation directions, then we can estimate the amplitude of anisotropy directly, by subtracting the phase-velocity curves for the fast and slow azimuths. If the paths are not exactly perpendicular, or if they do not align with the fast and slow directions exactly, then anisotropy will be underestimated. For reasonably small deviations, however, the error will be small, as the cosine function (which governs the $\pi$-periodic phase-velocity variations with azimuth) changes slowly near its extrema. Potential biases arising from lateral heterogeneity are reduced through the selection of paths that are within the same tectonic region and sample an approximately laterally homogeneous block. Importantly, our conclusions are based only on anisotropy patterns seen in several mutually consistent measurements. The direct estimates of anisotropy amplitude can show unambiguously where anisotropy is large, also confirming its orientation, thus providing useful inferences on the mechanisms of deformation in the crust and mantle.

\subsubsection{Path pairs and phase-velocity anisotropy}

We first select pairs of approximately perpendicular, "fast" and "slow" interstation paths that are parallel and perpendicular, respectively, to the fast-propagation directions of 15-40 s Rayleigh waves (Fig. 
8). In Central Qiangtang, differential dispersion (i.e., the difference between the "fast" and "slow" phase-velocity curves) consistently shows a 3 per cent peak between 20 and 35 s period, the period range most sensitive to the mid-crustal depths beneath Tibet (Fig. 5). A similar peak is also observed across northern Lhasa (ES01-H1370-ES11-ES42). In northeastern Tibet, the amplitude and width of the peaks of the differential dispersion curves vary with the orientation of the perpendicular paths, from $\sim 0$ per cent anisotropy for the path oriented W-E (USHU-WNDO) to $\sim 5$ per cent peak for the path oriented the NW-SE (BUDO-USHU).

One exception (Fig. 8, bottom left) is the path pair with one long, E-W path sampling along the southern boundary of the central and eastern Lhasa block and the other, $\mathrm{N}-\mathrm{S}$ path crossing westcentral Lhasa. The differential dispersion for this pair shows a clear positive peak at around $30 \mathrm{~s}$, but the dispersion curve for the eastern path is overall slower than for the western path. This difference is most likely due to these two paths sampling different isotropic-average structure. Although this example is extreme in the sense that these paths do not cross and sample overall different parts of Lhasa, the effect of isotropic heterogeneity should be of concern with the differential dispersion approach in general. We thus interpret only the results that are yielded consistently by different path pairs.

Across central and northeastern Tibet, the pattern of mid-crustal anisotropy is clear and consistent. Dispersion curves measured along near-W-E and near-N-S azimuths split naturally into faster and slower bundles, respectively, for periods between 20 and $35 \mathrm{~s}$ (Fig. 10, left)—supporting the assumption that the signal of anisotropy is dominant in the differential dispersion that we measure. The green arrows in Fig. 10 (centre) show the fast-propagation direction and the amplitude of anisotropy, measured as the average phase-velocity difference in the 20-35 s period range. Each arrow is oriented mid-angle between the azimuths parallel and perpendicular to the azimuths of the faster and slower path of the pair, respectively. In the background, the faster, E-W paths are plotted in pale blue and the slower, $\mathrm{N}-\mathrm{S}$ paths are plotted in pale red.

In order to measure azimuthal anisotropy in the upper mantle, we apply the differential dispersion approach to phase-velocity measurements at longer periods ( $>50 \mathrm{~s}$ ). Because the orientation of anisotropy in the upper mantle is different from that in the crust, the pairs of the "fast" and "slow" curves for differential dispersion analysis must also be different, chosen so as to match the fast and slow propagation azimuths at the longer periods. East-central Qiangtang is well sampled with interstation paths and shows significant phase-velocity dependence on azimuth (Fig. 4, 80 s). Fig. 9 illustrates the analysis of differential Rayleigh-wave dispersion with a focus on the longer periods. North-south trending station paths in East-central Qiangtang (AMDO-ERDO, AMDO-BUDO, and AMDO-USHU) have similarly fast dispersion curves, whereas west-east trending station paths (USHU-WNDO, ERDO-USHU, and BUDO-USHU) yield lower phase velocities, as we have seen 
already in anisotropic tomography and subregion-average inversions (Figs 6 and 7). In Fig. 11 (left) the faster and slower dispersion curves can be seen separating at periods greater than $50 \mathrm{~s}$; the average phase-velocity anisotropy at periods over $50 \mathrm{~s}$ is plotted with purple arrows in Fig. 11, centre.

\subsubsection{Inversion for shear-velocity azimuthal anisotropy}

In order to determine the distribution of shear-velocity anisotropy with depth, we invert the pairs of the fast and slow dispersion curves jointly, for one-dimensional (1-D) profiles of the isotropic-average shear speed $\left(V_{\text {fast }}+V_{\text {slow }}\right) / 2$ and of azimuthal anisotropy $\left(V_{\text {fast }}-V_{\text {slow }}\right) / 2$. The pairs of curves chosen to sample anisotropy in the crust (Fig. 8) and in the mantle (Fig. 9) can constrain $V_{\mathrm{S}}$ anisotropy within these layers. In the inversions, the entire depth ranges of the crust and upper mantle are parameterized, but the anisotropy is meaningful in those depth ranges (crust or upper mantle) for which the pairs were chosen, based on the roughly known orientations of anisotropy.

The inversion is a non-linear, Levenberg-Marquardt gradient search. At each step, synthetic phase velocities are computed directly from 1-D Earth models (Masters, http://geodynamics.org/cig/software/mineos), with no linearization at any stage. Parameterization of the inversions uses the same depth basis functions for the isotropic-average $V_{\mathrm{S}}$ and anisotropy profiles, both of which are regularized with mild damping. The models produced by the inversions are non-unique because of the trade-offs between the anisotropy within adjacent depth intervals. In the presence of noise in the measurements, this can bias the models. Importantly, the 1-D anisotropy profiles that we obtain within the same regions show very similar structure, which suggests that the basic features of these profiles, which we interpret here, are robust. Inversion trade-offs and model non-uniqueness for Tibet were investigated in detail in Agius \& Lebedev (2013, 2014). Agius \& Lebedev (2014) showed that at least four layers are necessary to parameterize the Tibetan crust. Here, we use four layers in the crust, with the depths of the four discontinuities at the bottom of the layers also inversion parameters. In the mantle, 10 triangular basis functions are used (Agius \& Lebedev 2013, 2014).

Figs 8 and 9 display the resulting 1-D, $V_{\mathrm{S}}$ models (isotropic average and azimuthal anisotropy) for the crust and mantle, respectively. The synthetic dispersion curves for all the $V_{\mathrm{SV}}$ models fit the data closely (numerous examples of the data fits were shown and discussed in detail in Agius \& Lebedev $(2013,2014)$ ). The synthetic differential dispersion (the difference between the synthetic phase-velocity curves-green lines in middle frame within each subcolumn) matches the measurements closely in most cases, with the remaining oscillatory misfits likely due to frequency-dependent noise in the data. 


\subsection{The multi-layered azimuthal anisotropy}

Figs 10 and 11 summarize the spatial distribution of azimuthal anisotropy in the middle crust and upper mantle, respectively. The amplitudes of both phase-velocity anisotropy and $V_{\mathrm{S}}$ anisotropy at depth are constrained by the differential dispersion analysis. The mid-crustal layer with strong azimuthal anisotropy between 20 and $45 \mathrm{~km}$ depth, coincides with a Low-Velocity Zone (LVZ). $V_{\text {SV }}$ anisotropy in this layer has an amplitude of about 5 per cent in most locations in central Tibet (Fig. 10). In eastern and northeastern Tibet, the anisotropy amplitude we derive varies from 2 to $\sim 7.5$ per cent (Fig. 10).

In the upper $150 \mathrm{~km}$ of the mantle beneath east-central Tibet, the fast-propagation direction is SSW-NNE (Fig. 9). The 1-D shear-velocity models indicate that the azimuthal anisotropy is within a layer with low isotropic-average velocity, most of which must be the Tibetan asthenosphere (Agius \& Lebedev 2013; Vozar et al. 2014). This layer is above a very pronounced high-velocity anomaly, almost certainly associated with the Indian lithosphere that is subducting at a shallow angle beneath this part of Tibet (Agius \& Lebedev 2013). The average amplitude of the $S$-velocity anisotropy in the asthenosphere beneath east-central Tibet is $3-4$ per cent (Fig. 11).

The multi-layered anisotropic structure of Tibet can also be solved for in a single differentialdispersion inversion, thanks to the fact that the fast directions in the middle crust and asthenospheric mantle are nearly perpendicular. Fig. 12 shows two examples of 1-D shear-velocity models for eastcentral Tibet. Substantial anisotropy is required by the data both in the middle crust and in the asthenosphere, with a change in the fast direction between the two layers of about $90^{\circ}$. This alternative inversion confirms the results in Figs 10 and 11. It also shows the maximum anisotropy in the upper mantle at around 150-km depth, confirming that it is associated with the flow in asthenosphere.

\section{DISCUSSION}

\subsection{Azimuthal and radial anisotropy beneath Tibet: A brief synthesis}

The presence of substantial azimuthal anisotropy beneath Tibet is well established in studies using different techniques and data types, including surface-wave imaging (e.g., Griot et al. 1998; Huang et al. 2004; Su et al. 2008; Yao et al. 2010; Yi et al. 2010; Yang et al. 2010b; Ceylan et al. 2012; Legendre et al. 2015; Pandey et al. 2015; Schaeffer et al. 2016; Xie et al. 2016; Chen et al. 2016), shear-wave splitting analysis (e.g., McNamara et al. 1994; Hirn et al. 1995; Sandvol et al. 1997; Sol et al. 2007; Zhao et al. 2010; Leon Soto et al. 2012; Eken et al. 2013; Chang et al. 2015; Wu et al. 2015a; Chen et al. 2015; Liu et al. 2016; Singh et al. 2016; Ye et al. 2016), receiver functions (e.g., Vergne et al. 2003; Levin et al. 2008; Shen et al. 2015; Liu et al. 2015; Kong et al. 2016), attenuation studies (Bao et al. 2012) and P-wave arrival times (e.g., Wei et al. 2013; Huang et al. 2014; Zhang et al. 
2016b; Wei et al. 2016). Radial anisotropy (the difference between the vertically and horizontally polarized waves: $V_{\mathrm{SV}}$ and $V_{\mathrm{SH}}$, respectively, in the case of $S$ waves) is also well documented (e.g., Shapiro et al. 2004; Huang et al. 2010; Duret et al. 2010; Guo et al. 2012; Xie et al. 2013; Li et al. 2016).

In recent papers (Agius \& Lebedev 2013, 2014), we mapped radial anisotropy in the crust and upper mantle beneath Tibet using an approach similar to the one in this study-constraining the anisotropy amplitude as tightly as possible using specially selected, broadband surface-wave dispersion measurements. Here, we combine the evidence on the deformation beneath Tibet from seismic anisotropy (radial and azimuthal) determined both in our own work and the work of others.

Recent studies of azimuthal anisotropy beneath Tibet show increasing agreement regarding the dominant, large-scale pattern of fast-propagation azimuth distribution. In the mid-lower crust, it comprises E-W fast-propagation directions in central Tibet, NW-SE fast directions in northeastern Tibet, and N-S fast directions in eastern and southeastern Tibet. Schaeffer et al. (2016) mapped this pattern in their global waveform tomography of azimuthal anisotropy (their fig. 12, focussing on the India-Asia collision zone, 56-km depth). Pandey et al. (2015) mapped a similar pattern at a 75-km depth (the shallowest depth presented) in their regional, East-Asia, multimode-surface-wave tomography study. With data from over 2000 stations in Tibet and surroundings, Shen et al. (2016) and Xie et al. (2016) used ambient noise cross-correlations and achieved very dense regional data sampling; the dominant azimuthal anisotropy pattern they mapped within the high plateau is remarkably consistent with that given by the waveform tomography. The large-scale regional pattern varies so smoothly that it can be captured even by a tomographic inversion with only a few tens of paths (Fig. 6).

Our differential-dispersion inversion confirms this regional fast-azimuth pattern and yields the amplitudes of $V_{\mathrm{S}}$ anisotropy in the mid-lower crust (20-45 km depth range). The amplitude we determine is 3-5 per cent in southern Tibet (the Lhasa terrane), around 4-6 per cent in central Tibet, and 4-8 per cent in northeastern Tibet (Fig. 10).

At 150-200 km depths in the upper mantle, we map NNE-SSW anisotropy of 2-4 per cent beneath eastern and northeastern Tibet. In these locations, this depth range is occupied by the asthenosphere (Agius \& Lebedev 2013). Multi-mode surface wave tomography studies map anisotropy in the eastern Tibet with similar fast-propagation azimuths (Priestley et al. 2006; Pandey et al. 2015; Schaeffer et al. 2016).

Lateral variations in the strength of radial anisotropy are pronounced and different from those of azimuthal anisotropy. Radial anisotropy is particularly strong in the middle crust beneath central Tibet (Shapiro et al. 2004). Agius \& Lebedev (2014) mapped mid-crustal radial anisotropy ( $V_{\mathrm{SH}}>$ $\left.V_{\mathrm{SV}}\right)$ with amplitudes within 6-9 per cent and 5-8 per cent ranges in the west-central Lhasa and 
west-central Qiangtang, respectively, decreasing to 3-5 per cent in east-central Lhasa and 2-4 per cent in northeastern Qiangtang. In northeastern Tibet (eastern Songpan-Ganzi) radial anisotropy was not required by the data (although its presence was likely, the amplitude that fit the data was in the $0-5$ per cent range). In southeast Tibet, radial anisotropy was 3-6 per cent in northern and 4-7 per cent in southern Yunnan (Agius \& Lebedev 2014).

Shapiro et al. (2004) pointed out that the strong radial anisotropy in the middle crust beneath the highest-elevation, central part of Tibet coincided with where extension and, thus, crustal flattening occurred at present. They showed that this anisotropy can be accounted for by a high degree of horizontal alignment of mica crystals, caused by the horizontal flow accommodating the flattening (see also Hacker et al. (2014)). Xie et al. (2013) used ambient-noise tomography to map mid-crustal radial anisotropy across eastern Tibet that had a spatial average of $4.8 \pm 1.4$ per cent and terminated abruptly near the boundaries of the high plateau. Agius \& Lebedev (2014) confirmed the strong radial anisotropy in central Tibet, as well as in Yunnan, where extension is also observed. Generally across Tibet, radial anisotropy in the middle crust is the largest where there is extension and where, by inference, crustal flattening and the horizontal alignment of the micas occur (Shapiro et al. 2004; Agius \& Lebedev 2014).

In summary, the recent studies of azimuthal and radial anisotropy in the middle crust show an emerging mutual agreement. The azimuthal-anisotropy fast-propagation directions follow a largescale, regional pattern: E-W in the central, highest-elevation Tibet and parallel to the plateau boundaries along its perimeter, rotating gradually from E-W in the north to NW-SE in the northeast and to $\mathrm{N}-\mathrm{S}$ in the east and southeast. The ranges of the amplitudes of anisotropy determined in this study and in the studies mentioned above tend to overlap at the same locations. Strong radial anisotropy is observed beneath western-central and south-east Tibet—-the regions undergoing extension,- - whereas northeastern Tibet is characterised by weaker radial anisotropy.

In the upper mantle beneath eastern Tibet, the NNE-SSW fast-propagation directions that we determine here are consistent with those in large-scale waveform tomography of Pandey et al. (2015) and Schaeffer et al. (2016). The amplitude of radial anisotropy in the upper mantle shows lateral variations different from those in the crust (Agius \& Lebedev 2014): upper-mantle radial anisotropy is the strongest beneath northeastern Tibet (3.4-8.6 per cent), weaker just beyond high-plateau boundaries, and weak in central Tibet (e.g., Agius \& Lebedev 2013; Zhang et al. 2016a). This probably reflects both the patterns of flow in the asthenosphere and the (also debated) configuration of the subducted Indian lithosphere beneath Tibet (e.g., Zhou \& Murphy 2005; Kind \& Yuan 2010; Mechie et al. 2011; Liang et al. 2012; Ceylan et al. 2012; Nunn et al. 2013; Agius \& Lebedev 2013; Zhang et al. 2015; Schaeffer \& Lebedev 2015; Shi et al. 2016; Sternai et al. 2016). 


\subsection{Origin of anisotropy and its relationship to deformation}

Azimuthal anisotropy in the Earth's upper mantle is mainly due to the crystallographic preferred orientation (CPO) of the highly anisotropic crystals of olivine, the dominant upper-mantle mineral. Radial anisotropy is thought to be due to the olivine crystals aligning their fast axes preferentially horizontally $\left(V_{\mathrm{SH}}>V_{\mathrm{SV}}\right)$ or vertically $\left(V_{\mathrm{SH}}<V_{\mathrm{SV}}\right)$. Given sufficient finite strain, the fast directions of the crystals will align with the direction of flow or the direction of maximum extension in the mantle (e.g., Park \& Levin 2002; Becker et al. 2006; Karato et al. 2008).

Radial anisotropy in the middle and lower crust is thought to be primarily due to near-horizontal alignment of the sheet-like crystals of mica (e.g., biotite and muscovite) (e.g., Shapiro et al. 2004; Meissner et al. 2006). It can be large: $V_{\mathrm{SH}}$ exceeds $V_{\mathrm{SV}}$ by up to $\sim 10$ per cent in central Tibet (e.g., Shapiro et al. 2004; Duret et al. 2010; Agius \& Lebedev 2014). The 10 per cent anisotropy can be accounted for by the flattening of an aggregate including 15 per cent biotite and 15 per cent muscovite (Shapiro et al. 2004). Deformation associated with crustal flattening in central Tibet and southeastern Tibet thus produces a high degree of horizontal crystal alignment, suggesting that the rate of the flow in the middle crust is higher than the modest rate of extension at the surface (Shapiro et al. 2004). In northeastern Tibet, strike-slip deformation may tend to align micas in a vertical plane, resulting in weak radial anisotropy as observed there (Agius \& Lebedev 2014).

Azimuthal anisotropy in the mid-lower crust is the least well understood. It has been attributed primarily to the CPO of the mineral amphibole (e.g., Tatham et al. 2008), with recent experiments at high pressure and temperature confirming that deformed amphibole produces strong seismic anisotropy (Ko \& Jung 2015). Ko \& Jung (2015) also reported that three types of CPO could occur, depending on temperature and stress, which would complicate the interpretation of anisotropy. However, no evidence for the occurrence of the new CPO types has yet been found in rocks from Tibet (Ji et al. 2015).

Analysis of a large set of mica- and amphibole-bearing metamorphic rocks from SE Tibet performed by Ji et al. (2015) showed significant departures from transverse isotropy (as would be caused by the alignment of micas alone). Amphibole, kyanite, and sillimanite developed strong CPOs with fast axes parallel to the lineation (i.e., transport direction), which caused the schists to switch from hexagonal to orthorhombic symmetry. P wave anisotropy for the samples with $3.4,15$, and 30 per cent biotite was calculated to be $3.3,13.2$, and 16.3 per cent, respectively. However, the orthorhombic anisotropy in the samples was weaker for $\mathrm{S}$ waves compared to $\mathrm{P}$ waves (Ji et al. 2015).

Xie et al. (2015) proposed that both radial and azimuthal surface-wave anisotropy may be mainly due to hexagonal anisotropy of micas, aligned with tilted symmetry axes. Xie et al. (2016) inverted a large dataset of Rayleigh and Love wave phase velocities measured across eastern Tibet and showed 
that it was possible to fit the data with two layers (the upper crust and the mid-lower crust) with different tilted-axis hexagonal anisotropy within each. This result does not rule out the occurrence of different types of anisotropy within the mid-lower crust (including anisotropy with both hexagonal and orthorhombic symmetries), but highlights the ambiguity in the interpretation of crustal anisotropy (which is emerging as an exciting challenge in itself).

Empirical evidence on the relationship of anisotropy and deformation can be deduced from joint analysis of seismic measurements of anisotropy in the crust and the geological record of crustal deformation, where it is available and sufficient. Beneath the Cyclades (Greece) and Tuscany (Italy), for example - two locations of strong recent extension - fast-propagation directions in the lower crust inferred from surface-wave anisotropy are parallel to the known directions of the lithospheric extension (Endrun et al. 2011; Lebedev et al. 2010) and to the directions of flow in the lower crust that accommodates the extension, according to the stretching lineations in metamorphic rocks found at the surface (e.g., Jolivet et al. 2009; Tirel et al. 2009) and to geodynamic modelling of the flow (e.g., Tirel et al. 2008, 2013). These results provide strong evidence for the fast-propagation directions of azimuthal anisotropy in the mid-lower crust to align with the direction of the lithospheric extension and the direction of the mid-lower crustal flow that accommodates it.

\subsection{Origin of shear-wave splitting beneath Tibet}

Of the techniques widely used to detect azimuthal anisotropy, shear-wave splitting analysis offers high lateral but low vertical resolution. Surface-wave imaging, in contrast, has lower lateral resolution (depending on the lateral data sampling) but offers useful depth resolution, thanks to the frequency dependence of the depth ranges that surface waves sample. Surface waves can thus help in identifying the depth ranges in which the observed shear-wave splitting occurs.

Numerous shear-wave splitting measurements made across Tibet over more than two decades combine into a generally consistent, large-scale pattern of fast-propagation azimuths (Figs 1 and 13). However, on a closer inspection, the measurements display certain persistent inconsistencies: neighbouring stations show large differences in the splitting times and fast azimuths. In central and northeastern Tibet, in particular, there appear to be two different fast-propagation azimuths that occur frequently, one E-W (rotating to NW-SE as we go eastward) and the other NE-SW (Fig. 13).

Although most shear-wave splitting analyses have been performed under the assumption that the splitting originates within a single anisotropic layer, observed variations in shear-wave splitting parameters as a function of back azimuth (azimuth from the station towards the earthquake epicentre) suggest multiple anisotropic layers with different orientations of anisotropic fabric within each (e.g., Silver \& Savage 1994; Savage 1999; Levin et al. 1999). Gao \& Liu (2009) reported two layers with 
significant anisotropy beneath the station Lhasa, previously marked with null measurements when the data were processed assuming a single anisotropic layer. Two-layer modelling of shear-wave splitting has also been carried out at a number of other sites within the plateau (Levin et al. 2008; Huang et al. 2011; Li et al. 2011; Levin et al. 2012; Wu et al. 2015b; Ye et al. 2016).

In continents with normal crustal thickness, the crustal contribution to SKS splitting is relatively small. In Tibet, however, the crust is a thick, highly anisotropic layer. Crustal anisotropy can thus have a major contribution to the observed SKS splitting, along with the anisotropy of the upper mantle, in particular the asthenosphere.

Our results show two main layers of azimuthal anisotropy beneath the central and northeastern Tibet (Figs 10 and 11), with the anisotropy within the mid-lower crust and the asthenosphere oriented differently. We can estimate SKS splitting accumulated within each of the two anisotropic layers. For a layer of thickness $L$, we estimate the shear wave splitting time $\delta t$ as:

$$
\delta t=\frac{L \delta \beta}{\beta_{o}}
$$

where $\beta_{o}$ is the average isotropic shear velocity in the layer, and $\delta \beta$ is the relative amplitude of $S$ velocity anisotropy (McNamara et al. 1994).

Fig. 13 shows estimated splitting times and fast-propagation directions that would be produced by anisotropy in the crust alone and in the upper mantle alone. For the crust, the splitting is estimated from $S$-velocity anisotropy of the entire crust (all four crustal layers); for the mantle-from $S$-velocity anisotropy from the Moho down to 200-km depth. The estimated splitting time accumulated in the crust alone is in the $0.25-0.8 \mathrm{~s}$ range; in the mantle-in the $0.5-1.2 \mathrm{~s}$ range. The net effect of the two anisotropic layers on the observed SKS waveforms will depend on the back azimuth (Silver \& Savage 1994; Savage 1999; Levin et al. 1999; Lev et al. 2006; Levin et al. 2008; Wang et al. 2008; Gao \& Liu 2009; Huang et al. 2011; Li et al. 2011; Levin et al. 2012; Wu et al. 2015b). Computation of predicted SKS splitting with specific splitting analysis methods is beyond the scope of this paper, but we can infer, qualitatively, that the dominant E-W (central Tibet) and NW-SE (eastern Tibet) fastpropagation directions, as seen in the SKS-splitting observations (Fig. 13) are, at least in large part, due to anisotropy in the crust, whereas the NE-SW fast directions reflect anisotropy in the asthenosphere.

\subsection{Mechanisms of crustal thickening and plateau growth: Channel flow, pure shear or both?}

The thickness of the Tibetan crust varies substantially across the plateau. The greatest Moho depth values, 80-90 km, have been reported beneath western Tibet (e.g., Gilligan et al. 2015)) and at the eastern Hymalayan syntaxis (e.g., Priestley et al. 2008). In western Tibet, the crust may be about $80 \mathrm{~km}$ thick from Lhasa all the way up to Tarim Basin (Zhao et al. 2010); in the central Tibet the crust 
thins towards the north, northeast and south-east. Beneath central Lhasa the crustal thickness is about 75 km (e.g., Schulte-Pelkum et al. 2005; Nábelek et al. 2009), and to the north from there, in central Tibet, the Moho depth beneath Qiangtang decreases by about 10 km (e.g., Zhao et al. 2001; Kind et al. 2002; Kumar et al. 2006; Nábelek et al. 2009; Tseng et al. 2009; Gao et al. 2013). At the northern edge of the Tibetan Plateau the crust thins sharply from $\sim 65 \mathrm{~km}$ beneath the Songpan-Ganzi terrane to $\sim 50 \mathrm{~km}$ beneath the Qaidam Basin (Shi et al. 2009; Karplus et al. 2011; Yue et al. 2012), with the Kunlun Fault marking the boundary. Further to the east, the crust thins gradually to $\sim 40 \mathrm{~km}$ beneath the Qinling-Qilian orogen (Liu et al. 2006; Li et al. 2006). From central to eastern and south-eastern Tibet, the crust thins, gradually, to 50 and $40 \mathrm{~km}$ beneath North and South Yunnan, respectively (e.g., Wang et al. 2013; Kan et al. 1986; Li et al. 2006; Xu et al. 2007). The changes in the Moho topography and crustal thickness are reflected in the surface topography variations, particularly strong around the periphery of the high plateau.

GPS observations of the present-day vertical motions of the surface of the plateau show that locations in the central Tibet are either sinking or rising at a small rate, in contrast with locations in the east and northeast that rise at a high rate (Liang et al. 2013). This is consistent with the crustal thickness changing slowly beneath the high-elevation parts of the plateau, where the crust is not growing in thickness today, but increasing at a high rate in the eastern part, where the crust is thickening (Wang et al. 2014). (Mantle processes may also play a role in the evolution of topography: e.g., Molnar et al. 1993). Numerical models of the evolution of Tibet's crustal thickness highlight the relationships between surface motions and the stress-strain distribution at depth and the importance of data that can constrain deformation at depth (e.g., Baumann \& Kaus 2015).

The mid-lower Tibetan crust ( $>20 \mathrm{~km}$ depth) is characterised by very low shear velocities (e.g., Kind et al. 1996; Yang et al. 2012; Xie et al. 2013; Agius \& Lebedev 2014), high electrical conductivity (e.g., Chen et al. 1996; Wei et al. 2001; Rippe \& Unsworth 2010; Le Pape et al. 2012), high temperatures (e.g., Hacker et al. 2000; Mechie et al. 2004), and partial melting (Nelson et al. 1996; Yang et al. 2012; Agius \& Lebedev 2014). Importantly, geophysical imaging maps these properties as lateral averages over hundreds-of-kilometres scales, which means that they are pertinent to the large-scale dynamics of Tibet. Estimates for the viscosity of the middle crust beneath Tibet are at least an order of magnitude lower than the viscosity of the adjacent rocks (e.g., Beaumont et al. 2001; Unsworth et al. 2005; Caldwell et al. 2009). This weak layer can thus support flow driven by pressure gradients, which can be created by topography gradients. With the surface elevation decreasing from the central to eastern plateau, rapid eastward flow of the deep crust has been proposed to be the main cause of the late-Cenozoic crustal thickening and surface uplift in the eastern Tibetan (e.g., Royden et al. 1997; Clark \& Royden 2000; Klemperer 2006; Royden et al. 2008). 
Given the strong evidence for the weak mid-lower crustal layer, the once proposed strong mechanical coupling between the shallow crust, deep crust and the mantle lithosphere (e.g., Flesch et al. 2005; Wang et al. 2008) is unlikely, and the depth distribution of anisotropy yields specific evidence against this, as discussed below. The question, instead, is whether the flow in the deep crust follows the topography gradients, in which case it should be towards the east in east-central Tibet, towards southsoutheast in SE Tibet and towards northeast in NE Tibet, or whether, instead, the deformation in the shallow and deep crust is coherent, in the sense that the net deformation in the mid-lower crust and at the surface are similar (for example, the same directions of the net average extension or compression). Assuming that the fast-propagation direction of azimuthal anisotropy in the middle crust is parallel to the direction of horizontal flow, to the direction of maximum extension, or to the direction of shear in this layer (Lebedev et al. 2010; Endrun et al. 2011), a comparison of the inferred deformation in the middle crust and that at the surface can offer a discriminant.

At the surface, the southern and central parts of Tibet display north-south shortening and east-west extension (Fig. 2). The motion of the surface is towards NNE, parallel to the plate motion of India (Fig. 14). To the east, in the east-central and eastern plateau, the surface motion vectors rotate clockwise progressively, to north-eastward and eastward. Deformation in the northeastern part of the high plateau (eastern Songpan-Ganzi terrane, $>4 \mathrm{~km}$ elevation) is primarily left-lateral shear, with NE-SW average net compression and NW-SE average net extension. If we subtract the regionally dominant component of motion parallel to the motion of India (Fig. 14), with the vectors of this motion parallel to the $\mathrm{N} 20^{\circ} \mathrm{E}$ azimuth and decreasing in amplitude from south to north so as to fit the GPS data (Zhang et al. 2004), the remaining surface motion is towards E in central Tibet, towards ESE in northeastern Tibet and towards SE and SSE in eastern Tibet. These residual motion vectors are parallel to the maximum extension directions in central, northeastern and eastern Tibet (Fig. 2). The amplitudes of the residual surface-motion vectors increases from the central to eastern plateau.

In central Tibet, both the region-scale topography gradient (from the higher central towards the lower eastern Tibet) and the extension at the surface are E-W. Thus, the E-W fast-propagation direction observed in central Tibet's middle crust would be consistent both with its rapid eastward flow and with an E-W extension within it, as at the surface. However, the rate of extension at the surface is relatively low, whereas finite strain in the middle crust must be large, in order to account for the unusually large radial anisotropy there (Shapiro et al. 2004). The large radial anisotropy thus strongly suggests—as first shown by Shapiro et al. (2004)—channel flow in the middle crust (mid-crustal rocks moving relative to upper-crustal rocks). Azimuthal anisotropy then serves to show that the dominant direction of this flow beneath central Tibet is eastward.

In north-eastern Tibet (by which we mean the NE part of the high $(>4 \mathrm{~km})$ plateau, i.e., the east- 
ern Songpan-Ganzi terrane), the regional topography gradient is NNE, roughly perpendicular to the WNW-ESE and NW-SE extension directions (Fig. 2). The SSE fast-propagation directions in the middle crust that we observe are parallel to the net average extension at the surface, not to the topography gradient. This implies that the dominant pattern of deformation in the deep crust is similar to that in the upper crust, not to flow along topography gradients.

Although the net deformation of NE Tibet's crust is, in this sense, vertically coherent, the mechanisms of deformation in the brittle and ductile crust are different. In the brittle crust, the NW-SE extension is accommodated by strike-slip on E-W oriented faults (approximately $45^{\circ}$ to the slip on the faults), as shown by the earthquake focal mechanisms (Fig. 2). Extension in the ductile deep crust is not parallel to the faults but, instead, parallel to the net extension due to the slip on the distributed strike-slip faults (see also Wang et al. 2016). This shows that the flow in the viscous middle crust is decoupled from the motions of the upper crust.

Farther northeast, at the northeastern periphery of the plateau, north of $34-35^{\circ} \mathrm{N}$, the crust is thinner, surface elevation is lower, and deformation at the surface is predominantly compression, accommodated by WNW-ESE striking thrust faults (Fig. 2). A number of recent studies have focussed on the mechanisms of the on-going crustal thickening this region, seen as a key to understanding the mechanisms of the growth of the plateau (see Yuan et al. 2013, and references therein). The balanced cross-sections of Lease et al. (2012) suggested that the Cenozoic crustal thickening here could be accounted for by pure shear alone. The channel flow model, in contrast, invokes transport of mid-crustal material into this region from the central plateau (e.g., Royden et al. 2008).

Although our new measurements do not sample this far north, previous anisotropy studies suggest that the orientations of anisotropy are similar in the eastern Songpan-Ganzi Terrane (south of 34$35^{\circ} \mathrm{N}$ ) and the Qinling-Qilian Orogen (north of $34-35^{\circ} \mathrm{N}$ ) (Yang et al. 2010b; Xie et al. 2016). If channel flow parallel to topography gradients was the dominant deformation mechanism, pervasive north-eastward flow would occur beneath eastern Songpan-Ganzi. Instead, both our measurements and other studies (e.g., Yang et al. 2010b) show anisotropy that matches the net deformation at the surface (WNW-ESE shear), not NNE flow (Fig. 15). Therefore, even though seismic anisotropy does present evidence for the occurrence of decoupled flow in the middle crust, it also suggests that the dominant mechanism of the crustal thickening in NE Tibet is pure shear.

\subsection{Deformation in the Tibetan asthenosphere}

Shallow mantle azimuthal anisotropy, evidenced by our measurements, is most likely within the Tibetan asthenopshere, which can be identified by low isotropic-average shear velocities at 100-200 km depths, between the thin Tibetan lithosphere and the subducting Indian lithosphere, the latter char- 
acterized by high seismic velocities (Agius \& Lebedev 2013) (Figs 9 and 16). The SSW-NNE fast directions beneath central and eastern Tibet are parallel to the direction of India's plate motion with respect to stable Eurasia (N20 ${ }^{\circ} \mathrm{E}-\mathrm{N} 21^{\circ} \mathrm{E}$, Sella et al. 2002; Wang et al. 2001). The anisotropy is weak beneath south-central Lhasa and increases towards the north (Fig. 11). The asthenospheric anisotropy probably reflects the flow associated with the subduction of the Indian slab, sliding beneath the Tibetan asthenosphere (Fig. 16). Anisotropy and, by inference, deformation in the asthenosphere are entirely different from those in the crust.

\section{CONCLUSIONS}

Broad-band measurements of Rayleigh-wave phase velocities from pairs of stations across Tibet reveal distinct azimuthal anisotropy patterns in two period bands. Differential-dispersion and region-average inversions constrain significant anisotropy within the middle crust and the asthenosphere. Anisotropy and, by inference, deformation in the crust and asthenosphere are quite different.

Published recent models of anisotropy in the Tibetan middle-lower crust show an emerging agreement regarding its large-scale pattern, with fast-propagation directions rotating gradually from $\mathrm{E}-\mathrm{W}$ in central Tibet to NE-SW in north-eastern Tibet and to N-S in south-eastern Tibet. Recent waveformtomography models of upper-mantle anisotropy show NNE-SSW fast directions in the shallow mantle beneath the central and eastern Tibet. Our data resolve both of these patterns simultaneously, constrain the anisotropic layers to be within the middle crust and the asthenosphere, and put tight constraints on the anisotropy amplitude. The amplitude of azimuthal anisotropy within the middle crust $(20-45 \mathrm{~km}$ depth range) is 3-5 per cent in southern Tibet, 4-6 per cent in central Tibet, and 4-8 per cent in NE Tibet. In the asthenosphere, the NNE-SSW azimuthal anisotropy is in the 2-4 per cent range.

In the asthenosphere beneath central and eastern Tibet, fast-propagation directions are parallel to the SSW-NNE motion of India. They are likely to indicate the flow induced by the Indian slab, subducting beneath east-central Tibet at a shallow angle (Agius \& Lebedev 2013).

Deformation regimes in the middle crust of central and NE Tibet are different: radial anisotropy is very strong in central Tibet but is weaker in NE Tibet (e.g., Shapiro et al. 2004; Agius \& Lebedev 2014; Xie et al. 2013), whereas azimuthal anisotropy is moderate in central Tibet and stronger in NE Tibet.

In the middle crust of central Tibet, the E-W fast-propagation directions are parallel both to the direction of current extension and to the direction of the eastward channel flow, proposed previously to follow the pressure gradient due to the west-to-east topography decrease and to account for the late-Cenozoic thickening of the east-Tibetan crust (e.g., Clark \& Royden 2000; Royden et al. 2008). Assuming that azimuthal anisotropy in the middle crust aligns with the direction of extension or the di- 
rection of flow (e.g., Endrun et al. 2011), the observed anisotropy is consistent with the proposed channel flow but does not require it. Strong independent evidence for channel flow in central Tibet comes from the very large radial anisotropy there (Shapiro et al. 2004). Therefore, the combined evidence from anisotropy confirms the occurrence of the channel flow, with the E-W azimuthal anisotropy indicating its eastward direction.

In north-eastern part of the high-elevation Tibet (eastern Songpan-Ganzi Terrane), the dominant surface deformation is E-W shear but the large-scale topography gradient is SW-NE. Fast-propagation directions in the middle crust are parallel to the NW-SE direction of the net extension at the surface, not to the SW-NE topography gradient, and neither to the E-W striking faults. The middle-crustal rock thus must move substantially with respect to the upper-crustal rock. In the upper crust, deformation in the NE high Tibet is accommodated by strike-slip faulting; in the middle crust, it is accommodated by shear (or flow) oriented at $\sim 45^{\circ}$ to the slip on the faults.

Seismic anisotropy across Tibet reveals a complex pattern of crustal deformation. Large-scale, decoupled, viscous flow in the middle crust is evidenced beneath both the central and eastern high plateau. In central Tibet, combined radial and azimuthal anisotropy strongly suggest eastward channel flow. In NE Tibet, the dominant deformation pattern in the middle crust is NW-SE shear. This does not rule out some transport of mid-crustal material towards the plateau periphery but shows that this is not the dominant flow pattern. The apparent lack of pervasive, large-scale flow transporting substantial volumes of crustal rock from central Tibet towards its northeastern periphery implies that the crustal thickening in northeastern Tibet must occur primarily by pure shear (faulting and folding in the upper crust accompanied by viscous shortening in the mid-lower crust).

\section{ACKNOWLEDGMENTS}

We thank two anonymous reviewers and Editor Ana Ferreira for comments that helped improve this manuscript. Joanne Adam has written the code for the inversion of single-event, interstation measurements for region-average anisotropy (Fig. 7). The facilities of the IRIS Data Management System (IRIS Data Management Center) were used for access to waveform and metadata used in this study. Figures were made using Generic Mapping Tools (GMT) software (Wessel \& Smith 1998). This study was supported by Science Foundation Ireland grants 08/RFP/GEO1704, 09/RFP/GEO2550, and 13/CDA/2192. 


\section{REFERENCES}

Adam, J. M.-C. \& Lebedev, S., 2012. Azimuthal anisotropy beneath southern Africa from very broad-band surface-wave dispersion measurements, Geophys. J. Int., 191(1), 155-174.

Agius, M. R., 2013. The structure and dynamics of the lithosphere beneath Tibet from seismic surface-wave analysis, Ph.D. thesis, Trinity College Dublin.

Agius, M. R. \& Lebedev, S., 2013. Tibetan and Indian lithospheres in the upper mantle beneath Tibet: Evidence from broadband surface-wave dispersion, Geochem. Geophys. Geosyst., 14(10), 4260-4281.

Agius, M. R. \& Lebedev, S., 2014. Shear-velocity structure, radial anisotropy and dynamics of the Tibetan crust, Geophys. J. Int., 199(3), 1395-1415.

Banerjee, P., Bürgmann, R., Nagarajan, B., \& Apel, E., 2008. Intraplate deformation of the Indian subcontinent, Geophys. Res. Lett., 35(18), 1-5.

Bao, X., Sandvol, E., Chen, Y. J., Ni, J., Hearn, T., \& Shen, Y., 2012. Azimuthal anisotropy of Lg attenuation in eastern Tibetan Plateau, J. Geophys. Res., 117(B10), B10309.

Barazangi, M. \& Ni, J., 1982. Velocities and propagation characteristics of Pn and Sn beneath the Himalayan arc and Tibetan Plateau: Possible evidence for underthrusting of Indian continental lithosphere beneath Tibet, Geology, 10(4), 179-185.

Barruol, G. \& Kern, H., 1996. Seismic anisotropy and shear-wave splitting in lower-crustal and upper-mantle rocks from the Ivrea Zoneexperimental and calculated data, Phys. Earth Planet. In., 95(3-4), 175-194.

Baumann, T. \& Kaus, B. J., 2015. Geodynamic inversion to constrain the non-linear rheology of the lithosphere, Geophys. J. Int., 202(2), 1289-1316.

Beaumont, C., Jamieson, R. A., Nguyen, M. H., \& Lee, B., 2001. Himalayan tectonics explained by extrusion of a low-viscosity crustal channel coupled to focused surface denudation, Nature, 414(6865), 738-742.

Becker, T. W., Chevrot, S., Schulte-Pelkum, V., \& Blackman, D. K., 2006. Statistical properties of seismic anisotropy predicted by upper mantle geodynamic models, J. Geophys. Res., 111(B8).

Becker, T. W., Conrad, C. P., Schaeffer, A. J., \& Lebedev, S., 2014. Origin of azimuthal seismic anisotropy in oceanic plates and mantle, Earth Planet. Sci. Lett., 401, 236-250.

Becker, T. W., Schaeffer, A. J., Lebedev, S., \& Conrad, C. P., 2015. Toward a generalized plate motion reference frame, Geophys. Res. Lett., 42(9), 3188-3196, 2015GL063695.

Caldwell, W. B., Klemperer, S. L., Rai, S. S., \& Lawrence, J. F., 2009. Partial melt in the upper-middle crust of the northwest Himalaya revealed by Rayleigh wave dispersion, Tectonophysics, 477(1-2), 58-65.

Ceylan, S., Ni, J., Chen, J. Y., Zhang, Q., Tilmann, F., \& Sandvol, E., 2012. Fragmented Indian plate and vertically coherent deformation beneath eastern Tibet, J. Geophys. Res., 117(B11), B11303.

Chang, L., Wang, C., Ding, Z., You, H., Lou, H., \& Shao, C., 2015. Upper mantle anisotropy of the eastern Himalayan syntaxis and surrounding regions from shear wave splitting analysis, Sci. China Ser. D-Earth Sci., 58(10), 1872-1882.

Chen, H., Zhu, L., \& Su, Y., 2016. Low velocity crustal flow and crust-mantle coupling mechanism in Yunnan, $\{\mathrm{SE}\}$ Tibet, revealed by 3D S-wave velocity and azimuthal anisotropy , Tectonophysics, $\mathbf{6 8 5}, 8-20$. 
Chen, L., Booker, J. R., Jones, A. G., Wu, N., Unsworth, M. J., Wei, W., \& Tan, H., 1996. Electrically Conductive Crust in Southern Tibet from INDEPTH Magnetotelluric Surveying, Science, 274(5293), 16941696.

Chen, W.-p., Martin, M., Tseng, T.-1., Nowack, R. L., Hung, S.-H., \& Huang, B.-S., 2010. Shear-wave birefringence and current configuration of converging lithosphere under Tibet, Earth Planet. Sci. Lett., 295(1-2), 297-304.

Chen, Y., Li, W., Yuan, X., Badal, J., \& Teng, J., 2015. Tearing of the Indian lithospheric slab beneath southern Tibet revealed by SKS-wave splitting measurements, Earth Planet. Sci. Lett., 413, 13-24.

Clark, M. K. \& Royden, L. H., 2000. Topographic ooze: Building the eastern margin of Tibet by lower crustal flow, Geology, 28(8), 703-706.

Copley, A., Avouac, J.-P., \& Wernicke, B. P., 2011. Evidence for mechanical coupling and strong Indian lower crust beneath southern Tibet, Nature, 472(7341), 79-81.

Darbyshire, F. A. \& Lebedev, S., 2009. Rayleigh wave phase-velocity heterogeneity and multilayered azimuthal anisotropy of the Superior Craton, Ontario, Geophys. J. Int., 176(1), 215-234.

Deschamps, F., Lebedev, S., Meier, T., \& Trampert, J., 2008. Azimuthal anisotropy of Rayleigh-wave phase velocities in the east-central United States, Geophys. J. Int., 173(3), 827-843.

Duret, F., Shapiro, N. M., Cao, Z., Levin, V., Molnar, P., \& Roecker, S., 2010. Surface wave dispersion across Tibet: Direct evidence for radial anisotropy in the crust, Geophys. Res. Lett., 37(16), 1-5.

Eken, T., Tilmann, F., Mechie, J., Zhao, W., Kind, R., Su, H., Xue, G., \& Karplus, M., 2013. Seismic anisotropy from SKS splitting beneath northeastern Tibet, Bull. Seismol. Soc. Am., 103(6), 3362-3371.

Endrun, B., Lebedev, S., Meier, T., Tirel, C., \& Friederich, W., 2011. Complex layered deformation within the Aegean crust and mantle revealed by seismic anisotropy, Nature Geoscience, 4(3), 203-207.

Flesch, L. M., Holt, W. E., Silver, P. G., Stephenson, M., Wang, C.-Y., \& Chan, W. W., 2005. Constraining the extent of crust-mantle coupling in central Asia using GPS, geologic, and shear wave splitting data, Earth Planet. Sci. Lett., 238(1-2), 248-268.

Fu, Y. V., Chen, Y. J., Li, A., Zhou, S., Liang, X., Ye, G., Jin, G., Jiang, M., \& Ning, J., 2008. Indian mantle corner flow at southern Tibet revealed by shear wave splitting measurements, Geophys. Res. Lett., 35(2).

Gao, R., Chen, C., Lu, Z., Brown, L. D., Xiong, X., Li, W., \& Deng, G., 2013. New constraints on crustal structure and Moho topography in Central Tibet revealed by SinoProbe deep seismic reflection profiling, Tectonophysics, 606, 160-170.

Gao, S. S. \& Liu, K. H., 2009. Significant seismic anisotropy beneath the southern Lhasa Terrane, Tibetan Plateau, Geochem. Geophys. Geosyst., 10(2), 1-19.

Ge, W.-P., Molnar, P., Shen, Z.-K., \& Li, Q., 2015. Present-day crustal thinning in the southern and northern Tibetan Plateau revealed by GPS measurements, Geophys. Res. Lett., 42(13), 5227-5235.

Gilligan, A., Priestley, K. F., Roecker, S. W., Levin, V., \& Rai, S. S., 2015. The crustal structure of the western Himalayas and Tibet, J. Geophys. Res., 120(5), 3946-3964.

Griot, D., Montagner, J.-P., \& Tapponnier, P., 1998. Confrontation of mantle seismic anisotropy with two 
extreme models of strain, in central Asia, Geophys. Res. Lett., 25(9), 1447.

Guo, Z., Gao, X., Wang, W., \& Yao, Z., 2012. Upper- and mid-crustal radial anisotropy beneath the central Himalaya and southern Tibet from seismic ambient noise tomography, Geophys. J. Int., 189(2), 1169-1182.

Hacker, B. R., Gnos, E., Ratschbacher, L., Grove, M., Mcwilliams, M., Sobolev, S. V., Wan, J., \& Zhenhan, W., 2000. Hot and Dry Deep Crustal Xenoliths from Tibet, Science, 287(5462), 2463-2466.

Hacker, B. R., Ritzwoller, M. H., \& Xie, J., 2014. Partially melted, mica-bearing crust in Central Tibet, Tectonics, 33(7), 1408-1424, 2014TC003545.

Herquel, G. \& Tapponnier, P., 2005. Seismic anisotropy in western Tibet, Geophys. Res. Lett., 32(17), 2-5.

Hirn, A., Jiang, M., Sapin, M., Diaz, J., Nercessian, A., Lu, Q. T., Lépine, J. C., Shi, D. N., Sachpazi, M., Pandey, M. R., Ma, K., \& Gallart, J., 1995. Seismic anisotropy as an indicator of mantle flow beneath the Himalayas and Tibet, Nature, 375(6532), 571-574.

Huang, H., Yao, H., \& van der Hilst, R. D., 2010. Radial anisotropy in the crust of SE Tibet and SW China from ambient noise interferometry, Geophys. Res. Lett., 37(21), 1-5.

Huang, W.-C., Ni, J. F., Tilmann, F., Nelson, D., Guo, J., Zhao, W., Mechie, J., Kind, R., Saul, J., Rapine, R., \& Hearn, T. M., 2000. Seismic polarization anisotropy beneath the central Tibetan Plateau, J. Geophys. Res., 105(B12), 27979-27989.

Huang, Z., Peng, Y., Luo, Y., Zheng, Y., \& Wei, S., 2004. Azimuthal anisotropy of Rayleigh waves in East Asia, Geophys. Res. Lett., 31(15), 1-4.

Huang, Z., Wang, L., Zhao, D., Mi, N., \& Xu, M., 2011. Seismic anisotropy and mantle dynamics beneath China, Earth Planet. Sci. Lett., 306(1-2), 105-117.

Huang, Z., Wang, P., Zhao, D., Wang, L., \& Xu, M., 2014. Three-dimensional P wave azimuthal anisotropy in the lithosphere beneath China, J. Geophys. Res., 119(7), 5686-5712.

Hubbard, J. \& Shaw, J. H., 2009. Uplift of the Longmen Shan and Tibetan plateau, and the 2008 Wenchuan $(\mathrm{M}=7.9)$ earthquake, Nature, 458(7235), 194-197.

Ji, S., Shao, T., Michibayashi, K., Oya, S., Satsukawa, T., Wang, Q., Zhao, W., \& Salisbury, M. H., 2015. Magnitude and symmetry of seismic anisotropy in mica- and amphibole-bearing metamorphic rocks and implications for tectonic interpretation of seismic data from the southeast Tibetan Plateau, J. Geophys. Res., 120(9), 6404-6430.

Jolivet, L., Faccenna, C., \& Piromallo, C., 2009. From mantle to crust: Stretching the Mediterranean, Earth Planet. Sci. Lett., 285(1-2), 198-209.

Kan, R. J., Hu, H. X., Zeng, R. S., Mooney, W. D., \& McEvilly, T. V., 1986. Crustal Structure of Yunnan Province, People's Republic of China, from seismic refraction profiles, Science, 234(4775), 433-7.

Karato, S.-i., Jung, H., Katayama, I., \& Skemer, P., 2008. Geodynamic Significance of Seismic Anisotropy of the Upper Mantle: New Insights from Laboratory Studies, Annual Review of Earth and Planetary Sciences, 36(1), 59-95.

Karplus, M. S., Zhao, W., Klemperer, S. L., Wu, Z., Mechie, J., Shi, D., Brown, L. D., \& Chen, C., 2011. Injection of Tibetan crust beneath the south Qaidam Basin: Evidence from INDEPTH IV wide-angle seismic 
data, J. Geophys. Res., 116(B7), 1-23.

Kind, R. \& Yuan, X., 2010. Seismic images of the biggest crash on Earth, Science, 329(5998), 1479-80.

Kind, R., Ni, J., Zhao, W., Wu, J., Yuan, X., Zhao, L., Sandvol, E., Reese, C., Nabelek, J., \& Hearn, T., 1996. Evidence from Earthquake Data for a Partially Molten Crustal Layer in Southern Tibet, Science, 274(5293), 1692-1694.

Kind, R., Yuan, X., Saul, J., Nelson, D., Sobolev, S. V., Mechie, J., Zhao, W., Kosarev, G., Ni, J., Achauer, U., \& Jiang, M., 2002. Seismic images of crust and upper mantle beneath Tibet: evidence for Eurasian plate subduction, Science, 298(5596), 1219-1221.

Klemperer, S., 2006. Crustal flow in Tibet: geophysical evidence for the physical state of Tibetan lithosphere, and inferred patterns of active flow, Geological Society, London, Special, 268, 39-70.

Ko, B. \& Jung, H., 2015. Crystal preferred orientation of an amphibole experimentally deformed by simple shear, Nature, 6, 6586.

Kong, F., Wu, J., Liu, K. H., \& Gao, S. S., 2016. Crustal anisotropy and ductile flow beneath the eastern Tibetan Plateau and adjacent areas, Earth Planet. Sci. Lett., 442, 72-79.

Kreemer, C., Holt, W. E., \& Haines, A. J., 2003. An integrated global model of present-day plate motions and plate boundary deformation, Geophys. J. Int., 154(1), 8-34.

Kumar, M. R. \& Singh, A., 2008. Evidence for plate motion related strain in the Indian shield from shear wave splitting measurements, J. Geophys. Res., 113(B8), 1-14.

Kumar, P., Yuan, X., Kind, R., \& Ni, J., 2006. Imaging the colliding Indian and Asian lithospheric plates beneath Tibet, J. Geophys. Res., 111(B6), 1-11.

Le Pape, F., Jones, A. G., Vozar, J., \& Wenbo, W., 2012. Penetration of crustal melt beyond the Kunlun Fault into northern Tibet, Nature, 5(5), 330-335.

Lease, R. O., Burbank, D. W., Zhang, H., Liu, J., \& Yuan, D., 2012. Cenozoic shortening budget for the northeastern edge of the Tibetan Plateau: Is lower crustal flow necessary?, Tectonics, 31(3).

Lebedev, S. \& van der Hilst, R. D., 2008. Global upper-mantle tomography with the automated multimode inversion of surface and S -wave forms, Geophys. J. Int., 173(2), 505-518.

Lebedev, S., Nolet, G., Meier, T., \& van der Hilst, R. D., 2005. Automated multimode inversion of surface and S waveforms, Geophys. J. Int., 162(3), 951-964.

Lebedev, S., Meier, T., \& van der Hilst, R. D., 2006. Asthenospheric flow and origin of volcanism in the Baikal Rift area, Earth Planet. Sci. Lett., 249(3-4), 415-424.

Lebedev, S., Endrun, B., Meier, T., Adam, J., \& Tirel, C., 2010. 3D deformation and evolution of Mediterranean basins: Insights From crustal and mantle anisotropy, in AGU Fall Meeting Abstracts.

Legendre, C. P., Deschamps, F., Zhao, L., \& Chen, Q.-F., 2015. Rayleigh-wave dispersion reveals crust-mantle decoupling beneath eastern Tibet, Scientific Reports, 5(1), 16644.

Leon Soto, G., Sandvol, E., Ni, J. F., Flesch, L. M., Hearn, T. M., Tilmann, F., Chen, Y. J., \& Brown, L., 2012. Significant and Vertically Coherent Seismic Anisotropy Beneath Eastern Tibet, J. Geophys. Res., 117.

Lev, E., Long, M. D., \& van der Hilst, R. D., 2006. Seismic anisotropy in Eastern Tibet from shear wave 
splitting reveals changes in lithospheric deformation, Earth Planet. Sci. Lett., 251(3-4), 293-304.

Levin, V., Menke, W., \& Park, J., 1999. Shear wave splitting in the Appalachians and the Urals: A case for multilayered anisotropy, J. Geophys. Res., 104(B8), 17975-17993.

Levin, V., Roecker, S., Graham, P., \& Hosseini, A., 2008. Seismic anisotropy indicators in Western Tibet: Shear wave splitting and receiver function analysis, Tectonophysics, 462(1-4), 99-108.

Levin, V., Huang, G.-c. D., \& Roecker, S., 2012. Crust-mantle coupling at the northern edge of the Tibetan Plateau: Evidence from focal mechanisms and observations of seismic anisotropy, Tectonophysics.

Li, L., Li, A., Murphy, M. A., \& Fu, Y. V., 2016. Radial anisotropy beneath northeast Tibet, implications for lithosphere deformation at a restraining bend in the Kunlun fault and its vicinity, Geochem. Geophys. Geosyst.

Li, S., Mooney, W. D., \& Fan, J., 2006. Crustal structure of mainland China from deep seismic sounding data, Tectonophysics, 420, 239-252.

Li, Y., Wu, Q., Zhang, F., Feng, Q., \& Zhang, R., 2011. Seismic anisotropy of the Northeastern Tibetan Plateau from shear wave splitting analysis, Earth Planet. Sci. Lett., 304(1-2), 147-157.

Liang, S., Gan, W., Shen, C., Xiao, G., Liu, J., Chen, W., Ding, X., \& Zhou, D., 2013. Three-dimensional velocity field of present-day crustal motion of the Tibetan Plateau derived from GPS measurements, J. Geophys. Res., 118(10), 5722-5732.

Liang, X., Sandvol, E., Chen, Y. J., Hearn, T., Ni, J., Klemperer, S., Shen, Y., \& Tilmann, F., 2012. A complex Tibetan upper mantle: A fragmented Indian slab and no south-verging subduction of Eurasian lithosphere, Earth Planet. Sci. Lett., 333-334, 101-111.

Liu, M., Mooney, W. D., Li, S., Okaya, N., \& Detweiler, S., 2006. Crustal structure of the northeastern margin of the Tibetan Plateau from the Songpan-Ganzi terrane to the Ordos basin, Tectonophysics, 420(1-2), 253266.

Liu, S., Yang, J., Tian, B., \& Zheng, Y., 2016. Seismic Anisotropy Determined by Shear-Wave Splitting Beneath the Eastern Tibetan Plateau, Pure Appl. Geophys., 173(2), 439-445.

Liu, Z., Park, J., \& Rye, D. M., 2015. Crustal anisotropy in northeastern Tibetan Plateau inferred from receiver functions: Rock textures caused by metamorphic fluids and lower crust flow?, Tectonophysics, 661, 66 - 80 .

McNamara, D. E., Owens, T. J., Silver, P. G., \& Wu, F. T., 1994. Shear wave anisotropy beneath the Tibetan Plateau, J. Geophys. Res., 99(B7), 13655-13665.

Mechie, J., Sobolev, S., Ratschbacher, L., Babeyko, A. Y., Bock, G., Jones, A., Nelson, K., Solon, K., Brown, L., \& Zhao, W., 2004. Precise temperature estimation in the Tibetan crust from seismic detection of the $\alpha-\beta$ quartz transition, Geology, 32(7), 601-604.

Mechie, J., Kind, R., \& Saul, J., 2011. The seismological structure of the Tibetan Plateau crust and mantle down to $700 \mathrm{~km}$ depth, Geological Society, London, Special Publications, 353(1), 109-125.

Meier, T., Dietrich, K., Stöckhert, B., \& Harjes, H.-P., 2004. One-dimensional models of shear wave velocity for the eastern Mediterranean obtained from the inversion of Rayleigh wave phase velocities and tectonic implications, Geophys. J. Int., 156(1), 45-58. 
Meissner, R., Rabbel, W., \& Kern, H., 2006. Seismic lamination and anisotropy of the Lower Continental Crust, Tectonophysics, 416(1-4), 81 - 99.

Meltzer, A. \& Christensen, N., 2001. Nanga Parbat crustal anisotropy: Implications for interpretation of crustal velocity structure and shearwave splitting, Geophys. Res. Lett., 28(10), 2129.

Molnar, P., England, P., \& Martinod, J., 1993. Mantle dynamics, uplift of the Tibetan Plateau, and the Indian Monsoon, Rev. Geophys., 31(4), 357.

Nábelek, J., Hetényi, G., Vergne, J., Sapkota, S., Kafle, B., Jiang, M., Su, H., Chen, J., Huang, B.-S., \& the Hi-CLIMB Team, 2009. Underplating in the Himalaya-Tibet collision zone revealed by the Hi-CLIMB experiment, Science, 325(5946), 1371-4.

Nábělek, J., Vergene, J., \& Hetenyi, G., 2005. Project Hi-CLIMB: a synoptic view of the Himalayan collision zone and Southern Tibet, in AGU Fall Meeting Abstracts, pp. T52A-02.

Nelson, K. D., Zhao, W., Brown, L. D., Kuo, J., Che, J., Liu, X., Klemperer, S. L., Makovsky, Y., Meissner, R., Mechie, J., Kind, R., Wenzel, F., Ni, J., Nabelek, J., Leshou, C., Tan, H., Wei, W., Jones, A. G., Booker, J., Unsworth, M., Kidd, W. S. F., Hauck, M., Alsdorf, D., Ross, A., Cogan, M., Wu, C., Sandvol, E., \& Edwards, M., 1996. Partially Molten Middle Crust Beneath Southern Tibet: Synthesis of Project INDEPTH Results, Science, 274(5293), 1684-1688.

Nishizawa, O. \& Yoshino, T., 2001. Seismic velocity anisotropy in mica-rich rocks: an inclusion model, Geophys. J. Int., 145(1), 19-32.

Nunn, C., Roecker, S. W., Tilmann, F. J., Priestley, K. F., Heyburn, R., Sandvol, E. a., Ni, J. F., Chen, Y. J., Zhao, W., \& Team, T. I., 2013. Imaging the lithosphere beneath NE Tibet: teleseismic P and S body wave tomography incorporating surface wave starting models, Geophys. J. Int., 196(3), 1724-1741.

Owens, T. J., Randall, G. E., Wu, F. T., \& Zeng, R., 1993. PASSCAL Instrument Performance During the Tibetan Plateau Passive Seismic Experiment, Bull. Seismol. Soc. Am., 83, 1959-1970.

Paige, C. C. \& Saunders, M. a., 1982. LSQR: An Algorithm for Sparse Linear Equations and Sparse Least Squares, Assoc. Comput. Mach. Trans. Math. Software, 8(1), 43-71.

Pandey, S., Yuan, X., Debayle, E., Tilmann, F., Priestley, K., \& Li, X., 2015. Depth-variant azimuthal anisotropy in Tibet revealed by surface wave tomography, Geophys. Res. Lett.

Park, J. \& Levin, V., 2002. Seismic Anisotropy: Tracing Plate Dynamics in the Mantle, Science, 296(5567), 485-489.

Priestley, K., Debayle, E., McKenzie, D., \& Pilidou, S., 2006. Upper mantle structure of eastern Asia from multimode surface waveform tomography, J. Geophys. Res., 111(B10).

Priestley, K., Jackson, J., \& McKenzie, D., 2008. Lithospheric structure and deep earthquakes beneath India, the Himalaya and southern Tibet, Geophys. J. Int., 172(1), 345-362.

Rippe, D. \& Unsworth, M., 2010. Quantifying crustal flow in Tibet with magnetotelluric data, Phys. Earth Planet. In., 179(3-4), 107-121.

Royden, L. H., Burchfiel, B. C., King, R. W., Wang, E., Chen, Z., Shen, F., \& Liu, Y., 1997. Surface deformation and lower crustal flow in eastern Tibet, Science, 276(5313), 788-790. 
Royden, L. H., Burchfiel, B. C., \& Hilst, R. D. v. d., 2008. The Geological Evolution of the Tibetan Plateau, Science, 321(5892), 1054-1058.

Sandvol, E., Ni, J., Kind, R., \& Zhao, W., 1997. Seismic anisotropy beneath the southern Himalayas-Tibet collision zone, J. Geophys. Res., 102(B8), 17813-17823.

Savage, M. K., 1999. Seismic anisotropy and mantle deformation: What have we learned from shear wave splitting?, Rev. Geophys., 37(1), 65.

Schaeffer, A. \& Lebedev, S., 2015. Global heterogeneity of the lithosphere and underlying mantle: A seismological appraisal based on multimode surface-wave dispersion analysis, shear-velocity tomography, and tectonic regionalization, in The Earth's Heterogeneous Mantle, Springer Geophysics, pp. 3-46, eds Khan, A. \& Deschamps, F., Springer International Publishing.

Schaeffer, A. J., Lebedev, S., \& Becker, T. W., 2016. Azimuthal seismic anisotropy in the Earth's upper mantle and the thickness of tectonic plates, Geophys. J. Int.

Schulte-Pelkum, V., Monsalve, G., Sheehan, A., Pandey, M. R., Sapkota, S., Bilham, R., \& Wu, F., 2005. Imaging the Indian subcontinent beneath the Himalaya, Nature, 435(7046), 1222-5.

Sella, G. F., Dixon, T. H., \& Mao, A., 2002. REVEL: A model for Recent plate velocities from space geodesy, J. Geophys. Res., 107(B4).

Shapiro, N. M., Ritzwoller, M. H., Molnar, P., \& Levin, V., 2004. Thinning and flow of Tibetan crust constrained by seismic anisotropy., Science, $\mathbf{3 0 5}(5681), 233-236$.

Shen, W., Ritzwoller, M. H., Kang, D., Kim, Y., Lin, F.-C., Ning, J., Wang, W., Zheng, Y., \& Zhou, L., 2016. A seismic reference model for the crust and uppermost mantle beneath China from surface wave dispersion, Geophys. J. Int., 206(2), 954-979.

Shen, X., Yuan, X., \& Ren, J., 2015. Anisotropic low-velocity lower crust beneath the northeastern margin of Tibetan Plateau: Evidence for crustal channel flow, Geochem. Geophys. Geosyst., 16(12), 4223-4236.

Shi, D., Shen, Y., Zhao, W., \& Li, A., 2009. Seismic evidence for a Moho offset and south-directed thrust at the easternmost Qaidam-Kunlun boundary in the Northeast Tibetan Plateau, Earth Planet. Sci. Lett., 288(1-2), 329-334.

Shi, D., Zhao, W., Klemperer, S. L., Wu, Z., Mechie, J., Shi, J., Xue, G., \& Su, H., 2016. West-east transition from underplating to steep subduction in the India-Tibet collision zone revealed by receiver-function profiles, Earth Planet. Sci. Lett., 452, 171-177.

Silver, P. G. \& Savage, M. K., 1994. The interpretation of shear-wave splitting parameters in the presence of two anisotropic layers, Geophys. J. Int., 119(3), 949-963.

Singh, A., Kumar, M. R., Raju, P. S., \& Ramesh, D. S., 2006. Shear wave anisotropy of the northeast Indian lithosphere, Geophys. Res. Lett., 33(16), 1-5.

Singh, A., Kumar, M. R., \& Raju, P. S., 2007. Mantle deformation in Sikkim and adjoining Himalaya: Evidences for a complex flow pattern, Phys. Earth Planet. In., 164(3-4), 232-241.

Singh, A., Eken, T., Mohanty, D. D., Saikia, D., Singh, C., \& Kumar, M. R., 2016. Significant seismic anisotropy beneath southern Tibet inferred from splitting of direct S-waves, Phys. Earth Planet. In., 250, 
$1-11$.

Smith, M. L. \& Dahlen, F. A., 1973. The azimuthal dependence of Love and Rayleigh wave propagation in a slightly anisotropic medium, J. Geophys. Res., 78(17), 3321-3333.

Sol, S., Meltzer, A., Bürgmann, R., van der Hilst, R., King, R., Chen, Z., Koons, P., Lev, E., Liu, Y., Zeitler, P., Zhang, X., Zhang, J., \& Zurek, B., 2007. Geodynamics of the southeastern Tibetan Plateau from seismic anisotropy and geodesy, Geology, 35(6), 563-566.

Soomro, R., Weidle, C., Cristiano, L., Lebedev, S., Meier, T., \& Group, P. W., 2016. Phase velocities of Rayleigh and Love waves in central and northern Europe from automated, broad-band, interstation measurements, Geophys. J. Int., 204(1), 517-534.

Sternai, P., Avouac, J.-P., Jolivet, L., Faccenna, C., Gerya, T., Becker, T. W., \& Menant, A., 2016. On the influence of the asthenospheric flow on the tectonics and topography at a collision-subduction transition zones: Comparison with the eastern Tibetan margin, J. Geodyn., 100, 184 - 197.

Su, W., Wang, C., \& Huang, Z., 2008. Azimuthal anisotropy of Rayleigh waves beneath the Tibetan Plateau and adjacent areas, Sci. China Ser. D-Earth Sci., 51(12), 1717-1725.

Tatham, D., Lloyd, G., Butler, R., \& Casey, M., 2008. Amphibole and lower crustal seismic properties, Earth Planet. Sci. Lett., 267(1-2), 118-128.

Taylor, M. \& Yin, A., 2009. Active structures of the Himalayan-Tibetan orogen and their relationships to earthquake distribution, contemporary strain field, and Cenozoic volcanism, Geosphere, 5(3), 199-214.

Tirel, C., Brun, J.-P., \& Burov, E., 2008. Dynamics and structural development of metamorphic core complexes, J. Geophys. Res., 113(B4), B04403.

Tirel, C., Gautier, P., Van Hinsbergen, D., \& Wortel, M., 2009. Sequential development of interfering metamorphic core complexes: numerical experiments and comparison with the Cyclades, Greece, Geological Society, London, Special Publications, 311(1), 257-292.

Tirel, C., Brun, J.-P., Burov, E., Wortel, M., \& Lebedev, S., 2013. A plate tectonics oddity: Caterpillar-walk exhumation of subducted continental crust, Geology, 41(5), 555-558.

Tseng, T.-1., Chen, W.-p., \& Nowack, R. L., 2009. Northward thinning of Tibetan crust revealed by virtual seismic profiles, Geophys. Res. Lett., 36(24).

Unsworth, M. J., Jones, A. G., Wei, W., Marquis, G., Gokarn, S. G., Spratt, J. E., Bedrosian, P., Booker, J., Leshou, C., Clarke, G., Shenghui, L., Chanhong, L., Ming, D., Sheng, J., Solon, K., Handong, T., Ledo, J., \& Roberts, B., 2005. Crustal rheology of the Himalaya and Southern Tibet inferred from magnetotelluric data, Nature, 438(7064), 78-81.

Vergne, J., Wittlinger, G., Farra, V., \& Su, H., 2003. Evidence for upper crustal anisotropy in the SongpanGanze (northeastern Tibet) terrane, Geophys. Res. Lett., 30(11), 11-14.

Vozar, J., Jones, A. G., Fullea, J., Agius, M. R., Lebedev, S., Le Pape, F., \& Wei, W., 2014. Integrated geophysical-petrological modeling of lithosphere-asthenosphere boundary in central Tibet using electromagnetic and seismic data, Geochem. Geophys. Geosyst., 15(10), 3965-3988.

Wang, C., Dai, J., Zhao, X., Li, Y., Graham, S. A., He, D., Ran, B., \& Meng, J., 2014. Outward-growth of the 
Tibetan Plateau during the Cenozoic: A review, Tectonophysics, 621, 1-43.

Wang, C.-y., Flesch, L. M., Silver, P. G., Chang, L.-J., \& Chan, W. W., 2008. Evidence for mechanically coupled lithosphere in central Asia and resulting implications, Geology, 36(5), 363.

Wang, E., Kirby, E., Furlong, K. P., van Soest, M., Xu, G., Shi, X., Kamp, P. J. J., \& Hodges, K. V., 2012. Two-phase growth of high topography in eastern Tibet during the Cenozoic, Nature Geoscience.

Wang, Q., Zhang, P. Z., Freymueller, J. T., Bilham, R., Larson, K. M., Lai, X., You, X., Niu, Z., Wu, J., Li, Y., Liu, J., Yang, Z., \& Chen, Q., 2001. Present-day crustal deformation in China constrained by global positioning system measurements, Science, 294(5542), 574-577.

Wang, Q., Niu, F., Gao, Y., \& Chen, Y., 2016. Crustal structure and deformation beneath the NE margin of the Tibetan plateau constrained by teleseismic receiver function data, Geophys. J. Int., 204(1), 167-179.

Wang, Y., Mooney, W. D., Yuan, X., \& Okaya, N., 2013. Crustal Structure of the Northeastern Tibetan Plateau from the Southern Tarim Basin to the Sichuan Basin, China, Tectonophysics, 584, 191-208.

Wei, W., Unsworth, M., Jones, A., Booker, J., Tan, H., Nelson, D., Chen, L., Li, S., Solon, K., Bedrosian, P., Jin, S., Deng, M., Ledo, J., Kay, D., \& Roberts, B., 2001. Detection of widespread fluids in the Tibetan crust by magnetotelluric studies, Science, 292(5517), 716-718.

Wei, W., Zhao, D., \& Xu, J., 2013. P-wave anisotropic tomography in Southeast Tibet: New insight into the lower crustal flow and seismotectonics, Phys. Earth Planet. In., 222, 47-57.

Wei, W., Zhao, D., Xu, J., Zhou, B., \& Shi, Y., 2016. Depth variations of P-wave azimuthal anisotropy beneath Mainland China, Scientific Reports, 6(February), 29614.

Weiss, T., Siegesmund, S., Rabbel, W., Bohlen, T., \& Pohl, M., 1999. Seismic Velocities and Anisotropy of the Lower Continental Crust: A Review, Pure Appl. Geophys., 156(1-2), 97-122.

Wessel, P. \& Smith, W. H. F., 1998. New, improved version of generic mapping tools released, Eos. Trans. $A G U, 79(47), 579-579$.

Wu, C., Xu, T., Badal, J., Wu, Z., \& Teng, J., 2015a. Seismic anisotropy across the Kunlun fault and their implications for northward transforming lithospheric deformation in northeastern Tibet, Tectonophysics, 659 , $91-101$.

Wu, J., Zhang, Z., Kong, F., Yang, B. B., Yu, Y., Liu, K. H., \& Gao, S. S., 2015b. Complex seismic anisotropy beneath western Tibet and its geodynamic implications, Earth Planet. Sci. Lett., 413(0), 167-175.

Xie, J., Ritzwoller, M. H., Shen, W., Yang, Y., Zheng, Y., \& Zhou, L., 2013. Crustal radial anisotropy across Eastern Tibet and the Western Yangtze Craton, J. Geophys. Res., 118(8), 4226-4252.

Xie, J., Ritzwoller, M. H., Brownlee, S., \& Hacker, B., 2015. Inferring the oriented elastic tensor from surface wave observations: preliminary application across the western United States, Geophys. J. Int., 201(2), 9961021.

Xie, J., Ritzwoller, M. H., Shen, W., \& Weitao, W., 2016. Crustal anisotropy across Eastern Tibet and surroundings modeled as a depth-dependent tilted hexagonally symmetric medium, Submitted to Geophys. J. Int. .

Xu, L., Rondenay, S., \& van der Hilst, R. D., 2007. Structure of the crust beneath the southeastern Tibetan 
Plateau from teleseismic receiver functions, Phys. Earth Planet. In., 165(3-4), 176-193.

Yang, Y., Zheng, Y., Chen, J., Zhou, S., Celyan, S., Sandvol, E., Tilmann, F., Priestley, K., Hearn, T. M., Ni, J. F., Brown, L. D., \& Ritzwoller, M. H., 2010a. Rayleigh wave phase velocity maps of Tibet and the surrounding regions from ambient seismic noise tomography, Geochem. Geophys. Geosyst., 11(8), 1-18.

Yang, Y., Zheng, Y., \& Ritzwoller, M. H., 2010b. Rayleigh-wave phase velocities and azimuthal anisotropy in Tibet and surrounding regions from ambient noise tomography, in Proceedings of the 25th HimalayaKarakoram-Tibet Workshop, U.S. Geological Survey, Open-File Report 2010-1099.

Yang, Y., Ritzwoller, M. H., Zheng, Y., Shen, W., Levshin, A. L., \& Xie, Z., 2012. A synoptic view of the distribution and connectivity of the mid-crustal low velocity zone beneath Tibet, J. Geophys. Res., 117(B4), $1-20$.

Yao, H., van der Hilst, R. D., \& Montagner, J.-P., 2010. Heterogeneity and anisotropy of the lithosphere of SE Tibet from surface wave array tomography, J. Geophys. Res., 115(B12).

Ye, Z., Li, Q., Gao, R., Zhang, H., Shen, X., Liu, X., \& Gong, C., 2016. Anisotropic regime across northeastern Tibet and its geodynamic implications, Tectonophysics, 671, $1-8$.

Yi, G.-X., Yao, H.-j., Zhu, J.-S., \& van der Hilst, R. D., 2010. Lithospheric deformation of continental China from Rayleigh wave azimuthal anisotropy, Chinese J. Geophys., 53(1), 121-135.

Yin, A. \& Harrison, T. M., 2000. Geologic Evolution of the Himalayan-Tibetan Orogen, Annu. Rev. Earth Planet. Sci., 28(1), 211-280.

Yuan, D.-Y., Ge, W.-P., Chen, Z.-W., Li, C.-Y., Wang, Z.-C., Zhang, H.-P., Zhang, P.-Z., Zheng, D.-W., Zheng, W.-J., Craddock, W. H., Dayem, K. E., Duvall, A. R., Hough, B. G., Lease, R. O., Champagnac, J.-D., Burbank, D. W., Clark, M. K., Farley, K. a., Garzione, C. N., Kirby, E., Molnar, P., \& Roe, G. H., 2013. The growth of northeastern Tibet and its relevance to large-scale continental geodynamics: A review of recent studies, Tectonics, 32(5), 1358-1370.

Yue, H., Chen, Y. J., Sandvol, E., Ni, J., Hearn, T., Zhou, S., Feng, Y., Ge, Z., Trujillo, A., Wang, Y., Jin, G., Jiang, M., Tang, Y., Liang, X., Wei, S., Wang, H., Fan, W., \& Liu, Z., 2012. Lithospheric and Upper Mantle Structure of the Northeastern Tibetan Plateau, J. Geophys. Res., 117, 1-18.

Zhang, H., Zhao, D., Zhao, J., \& Liu, H., 2015. Tomographic imaging of the underthrusting Indian slab and mantle upwelling beneath central Tibet, Gondwana Res., 28(1), 121-132.

Zhang, H., Zhao, D., Yu, C., \& Zhao, J., 2016a. Varying deformation patterns in central Tibet revealed by radial anisotropy tomography, J. Geophys. Res., 121(5), 3445-3461, 2016 JB012832.

Zhang, H., Zhao, J., Zhao, D., Yu, C., Liu, H., \& Hu, Z., 2016b. Complex deformation in western Tibet revealed by anisotropic tomography, Earth Planet. Sci. Lett., 451, 97 - 107.

Zhang, P.-Z., Shen, Z., Wang, M., Gan, W., Bürgmann, R., Molnar, P., Wang, Q., Niu, Z., Sun, J., Wu, J., Hanrong, S., \& Xinzhao, Y., 2004. Continuous deformation of the Tibetan Plateau from global positioning system data, Geology, 32(9), 809-812.

Zhang, S. \& Karato, S.-i., 1995. Lattice preferred orientation of olivine aggregates deformed in simple shear, Nature, 375(6534), 774-777. 


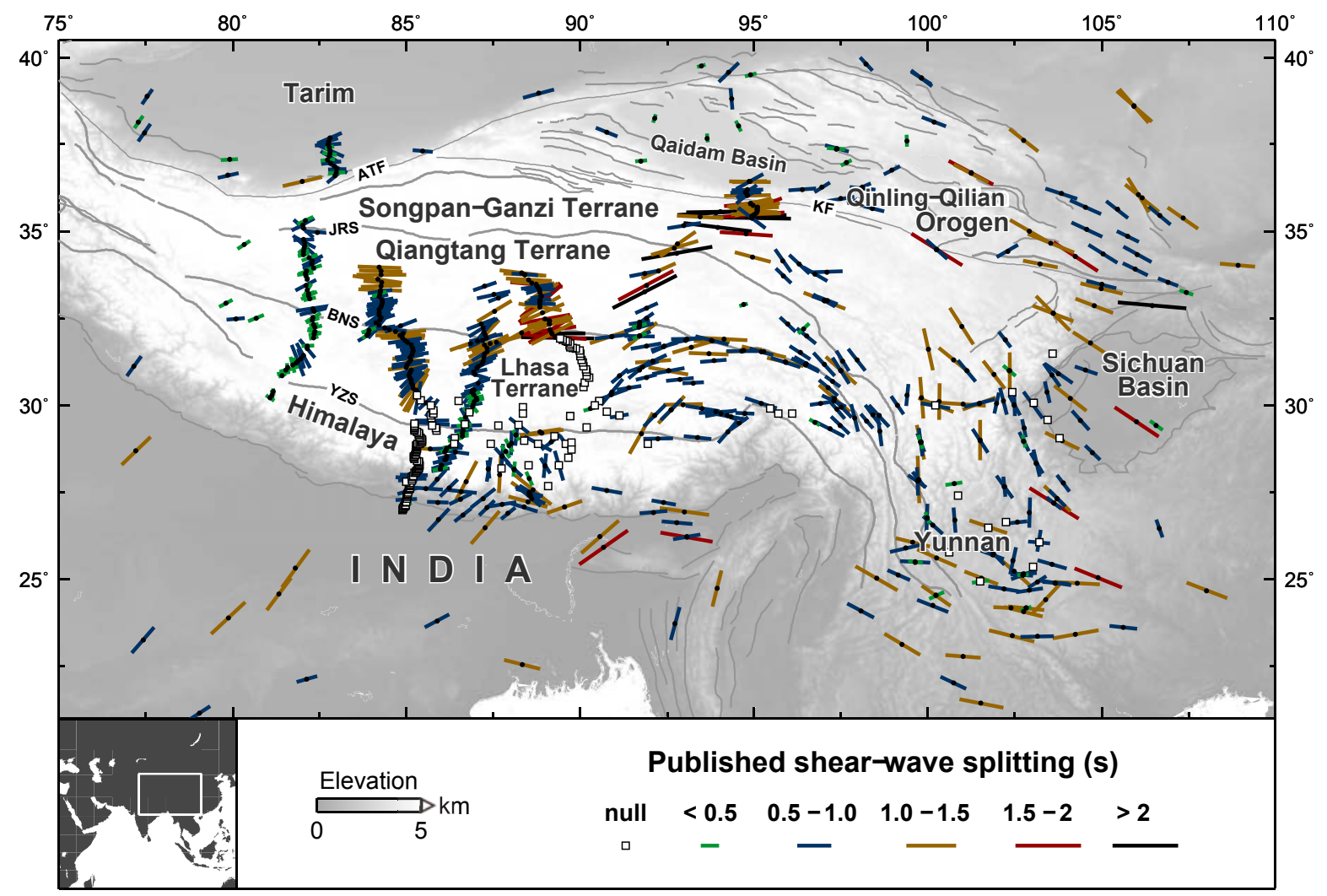

Figure 1. Map of the Tibetan Plateau and surrounding regions, showing a compilation of shear-wave splitting measurements using SKS and SKKS waves (McNamara et al. 1994; Hirn et al. 1995; Sandvol et al. 1997; Huang et al. 2000; Herquel \& Tapponnier 2005; Lev et al. 2006; Singh et al. 2006, 2007; Sol et al. 2007; Fu et al. 2008; Kumar \& Singh 2008; Wang et al. 2008; Chen et al. 2010; Zhao et al. 2010; Huang et al. 2011; Leon Soto et al. 2012). Colour and stick length both indicate the splitting time. Black circles are the locations of seismic stations. Black open squares are stations with reported null measurements. Grey lines show sutures and faults: YZS (Yarlung-Zangbo Suture), BNS (Bangong-Nujiang Suture), JRS (Jinsha River Suture), KF (Kunlun Fault) and ATF (Altyn Tagh Fault). Inset, bottom left: Location of the area on a large-scale regional map.

Zhang, X., Paulssen, H., Lebedev, S., \& Meier, T., 2009. 3D shear velocity structure beneath the Gulf of California from Rayleigh wave dispersion, Earth Planet. Sci. Lett., 279(3-4), 255 - 262.

Zhao, J., Yuan, X., Liu, H., Kumar, P., Pei, S., Kind, R., Zhang, Z., Teng, J., Ding, L., Gao, X., Xu, Q., \& Wang, W., 2010. The boundary between the Indian and Asian tectonic plates below Tibet, Proc. Nat. Acad. Sci., 107(25), 11229-33.

Zhao, W., Mechie, J., Brown, L. D., Guo, J., Haines, S., Hearn, T., Klemperer, S. L., Ma, Y. S., Meissner, R., Nelson, K. D., Ni, J. F., Pananont, P., Rapine, R., Ross, A., \& Saul, J., 2001. Crustal structure of central Tibet as derived from project INDEPTH wide-angle seismic data, Geophys. J. Int., 145(2), 486-498.

Zhou, H.-W. \& Murphy, M. A., 2005. Tomographic evidence for wholesale underthrusting of India beneath the entire Tibetan Plateau, J. Asian Earth Sci., 25(3), 445-457. 

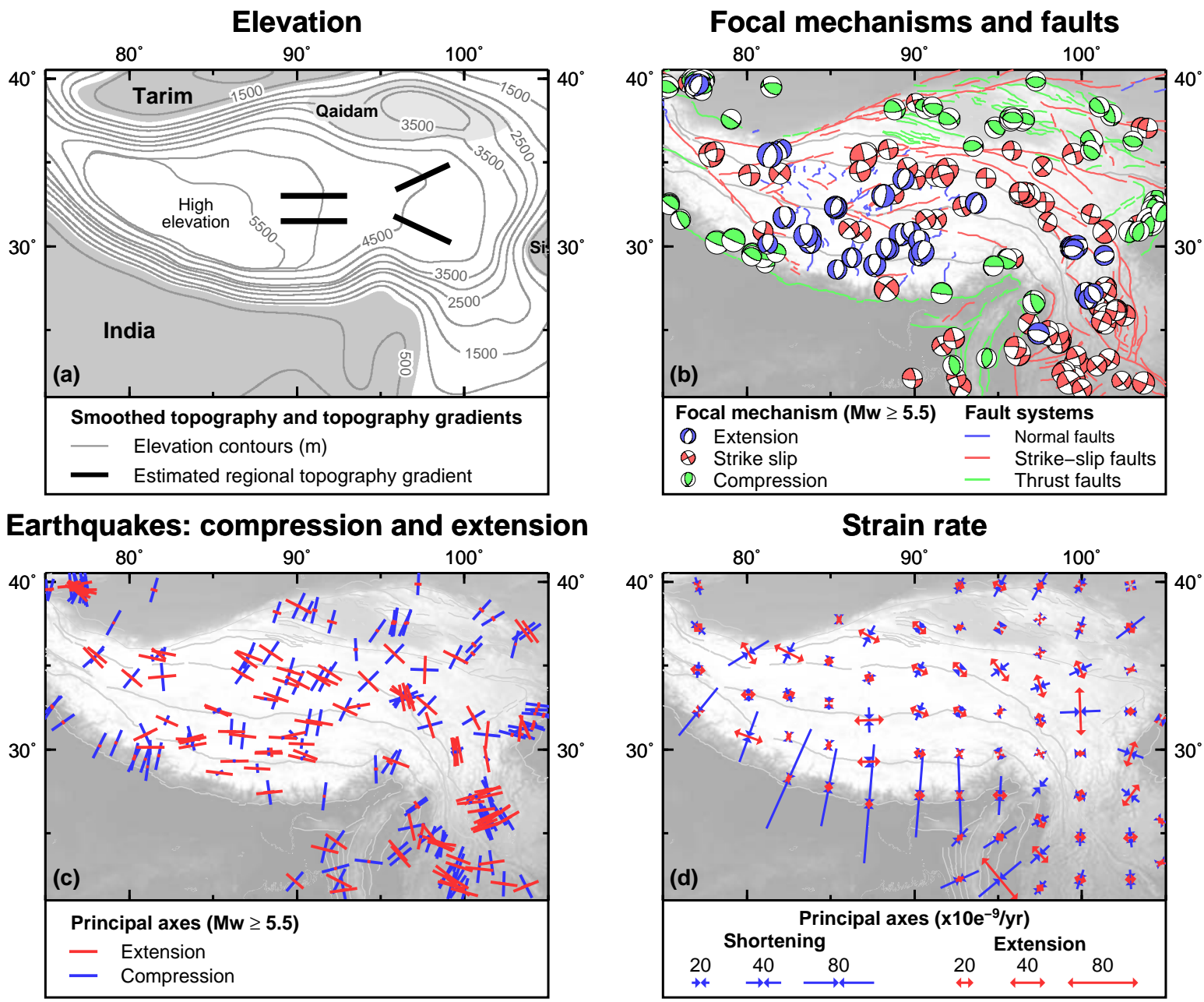

Figure 2. (a) Topography across the Tibetan Plateau. Black sticks are estimated regional topography gradients.

(b) Different fault systems colour-coded according to their type (normal, thrust, and strike-slip), from Taylor \& Yin (2009). Focal mechanisms shown are for earthquakes with $<50 \mathrm{~km}$ depth and with moment magnitude 25.5. The focal mechanisms are well-constrained double couple CMT solutions (http://www.globalcmt.org) colour-coded according to their mechanism (normal, compression, and strike-slip). Grey lines indicate sutures. (c) Principal axes of the horizontal components of the earthquake moment tensors, compression (blue sticks) and extension (red sticks), each normalized to the length of the largest axis. (d) Strain rate principal axes from the Global Strain Rate Map (GSRM) model (Kreemer et al. 2003). Blue, inward arrows denote compression (shortening). Red, outward arrows denote extension. 

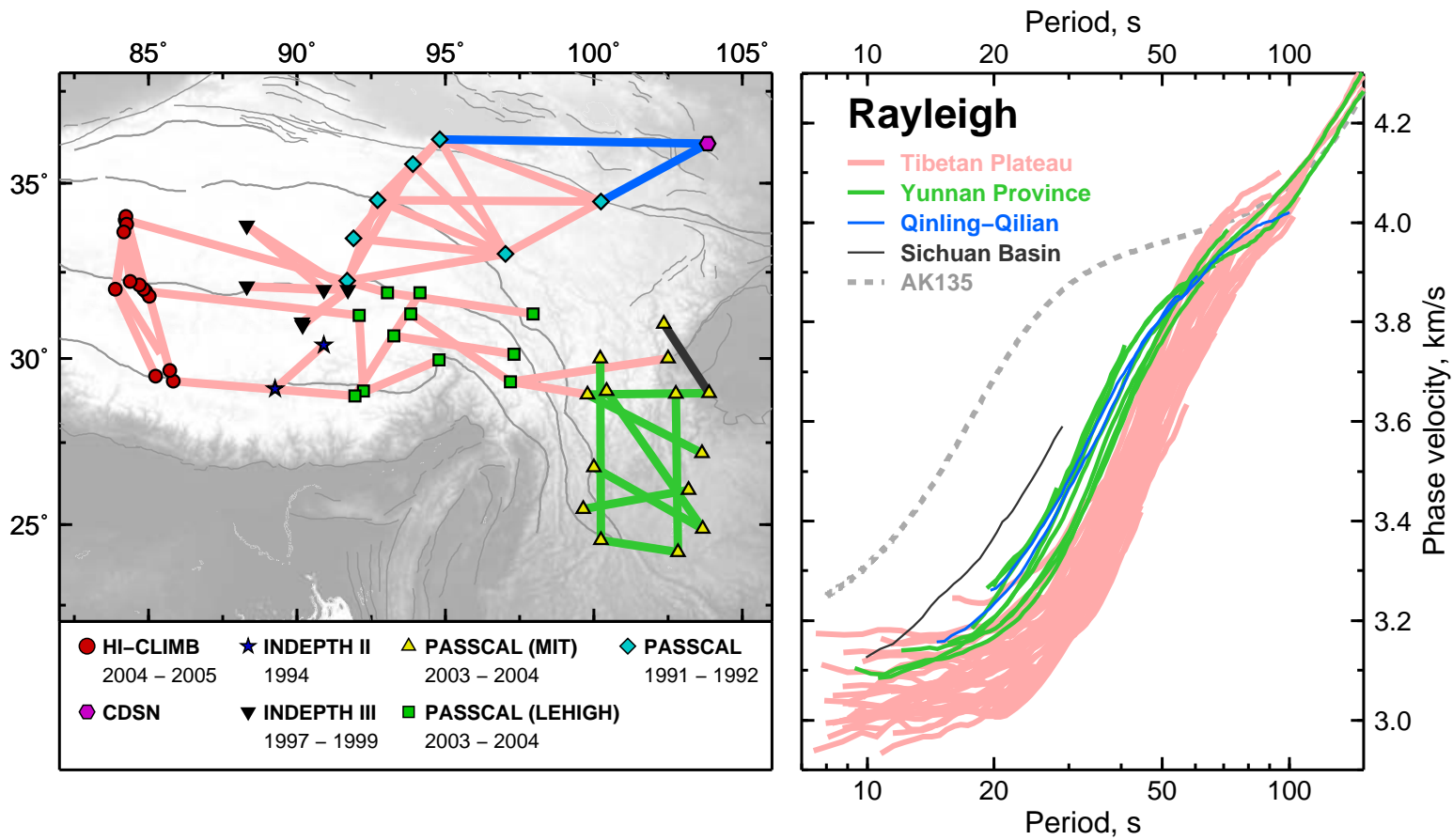

Figure 3. Broad-band, phase-velocity curves of the fundamental Rayleigh mode for interstation paths across the Tibetan Plateau. Left: The seismic stations and interstation paths used for the measurements. Different symbols correspond to different seismic networks, operated at specified times. Right: Dispersion curves for all the interstation paths, colour coded to represent different regions of the plateau. 

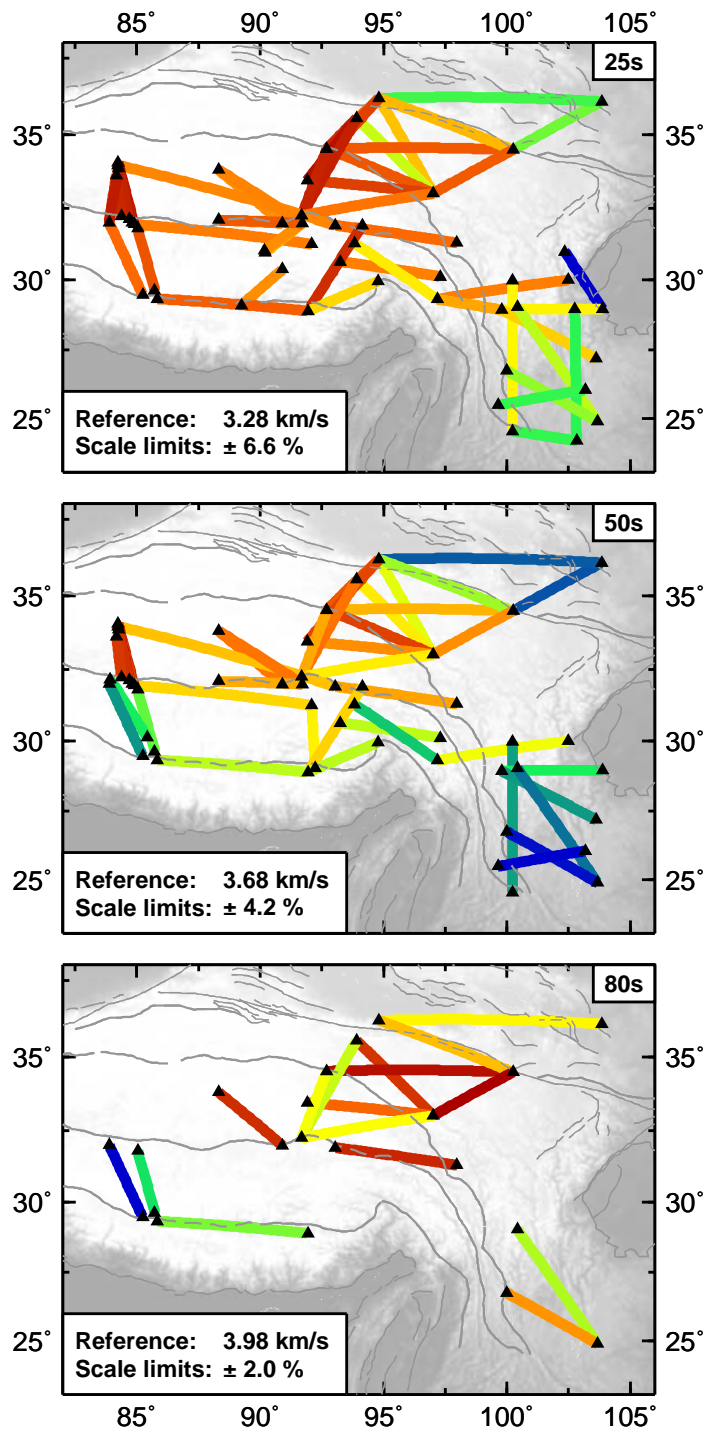

Rayleigh-wave phase-velocity anomaly

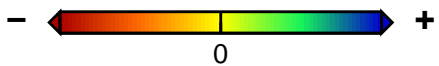

Figure 4. Rayleigh-wave, fundamental-mode, phase-velocity variations across the Tibetan Plateau at 25, 50 and $80 \mathrm{~s}$ periods. Coloured lines show the interstation paths between stations (black triangles). The colours indicate the deviation of the phase velocity along the path from the reference phase velocity at this period. The reference and the scale limits at each period are given within each of the frames. 


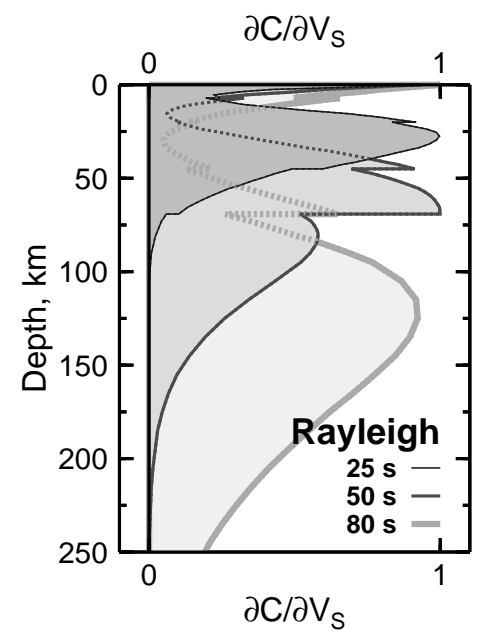

Figure 5. Depth sensitivity kernels for the phase velocities of the fundamental-mode Rayleigh waves. Different curves represent the Fréchet derivatives of phase velocities with respect to shear velocities for periods 25, 50 and 80 seconds, all scaled independently. These kernels are computed for a 1-D isotropic shear-velocity profile with a four-layer crust, a Moho discontinuity at $69 \mathrm{~km}$ depth, and seismic velocities typical for East-Central Qiangtang Terrane (Agius \& Lebedev 2013). 

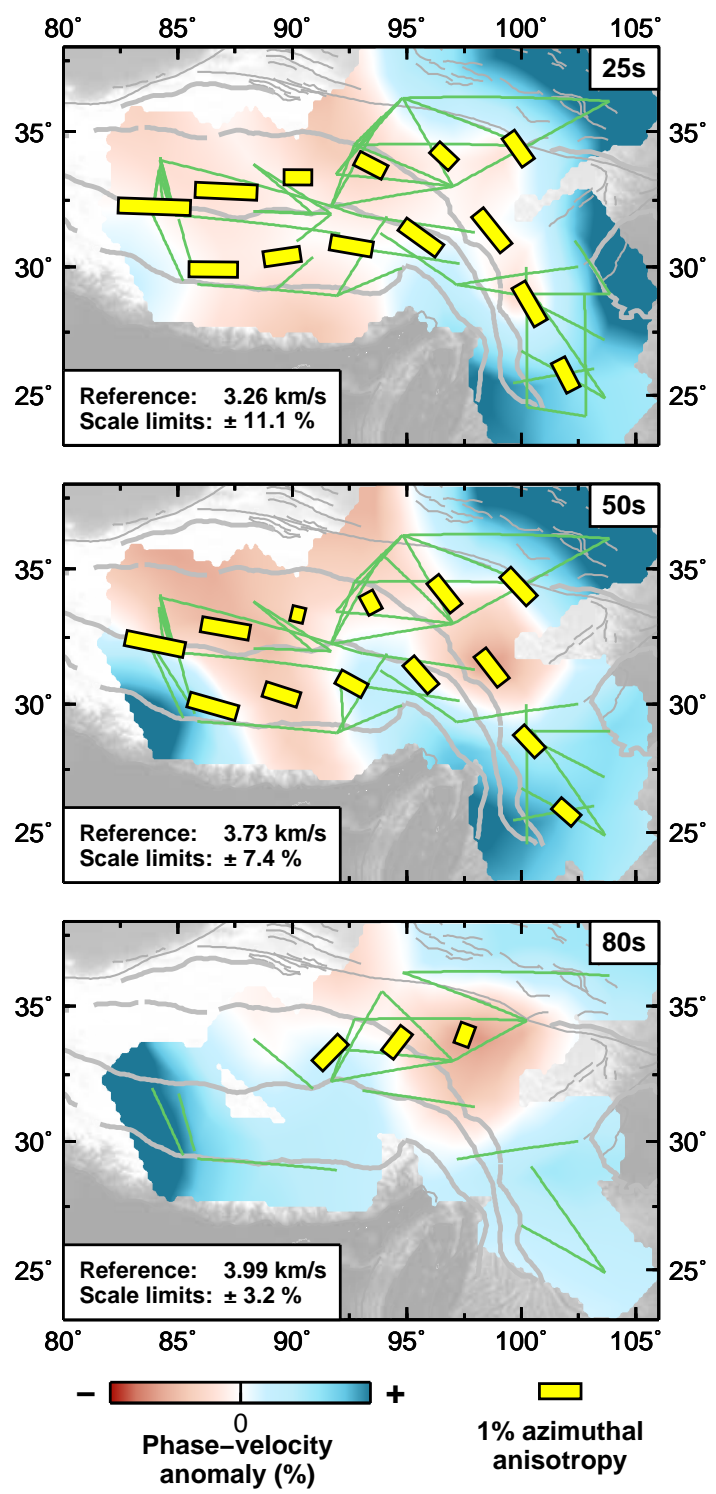

Figure 6. Phase-velocity maps at 25, 50 and 80 second periods. Grey lines are major tectonic boundaries across the plateau. Green lines indicate the interstation paths used. Red and blue shade shows relatively low and high isotropic phase velocity, respectively, relative to the reference (specified in each frame). Yellow sticks show the fast-propagation direction and amplitude of the $2 \psi$ anisotropy. 

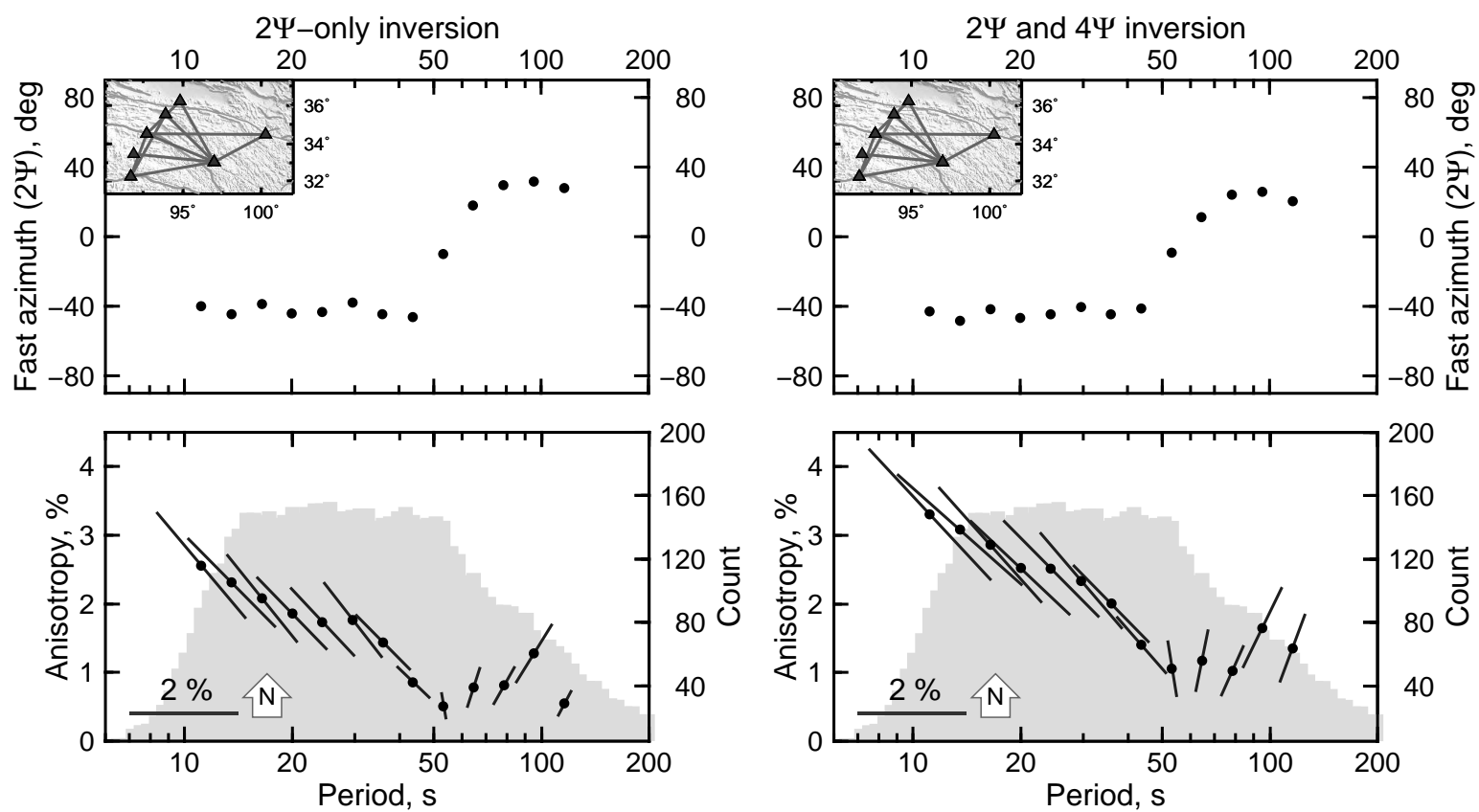

Figure 7. Phase-velocity azimuthal anisotropy in northeastern Tibet as a function of period, computed in regionaverage inversions. Left: inversion for $2 \psi$ terms only. Right: inversion for both $2 \psi$ and $4 \psi$ components of azimuthal anisotropy. The inversions use all single-event dispersion measurements from the station pairs within northeastern Tibet (inset maps). For each station pair, the measurements are for events with back-azimuths distributed within a $20^{\circ}$ azimuthal window $\left( \pm 10^{\circ}\right.$ from the interstation great circle path), resulting in sufficient azimuthal coverage for unambiguous retrieval of anisotropy (under the assumption of weak lateral heterogeneity within the sub-region). Top: Azimuth of the fast-propagation direction as a function of period. Zero represents North. Bottom: The left vertical axes and the length of the bars both indicate the amplitude of azimuthal anisotropy. The orientation of the bars shows the fast propagation direction as if viewed on a map ( $\mathrm{N}$ indicates North). The right vertical axes indicate the number of single-event measurements used at each period (light grey vertical bars). 
The crust: Phase-velocity and shear-velocity azimuthal anisotropy
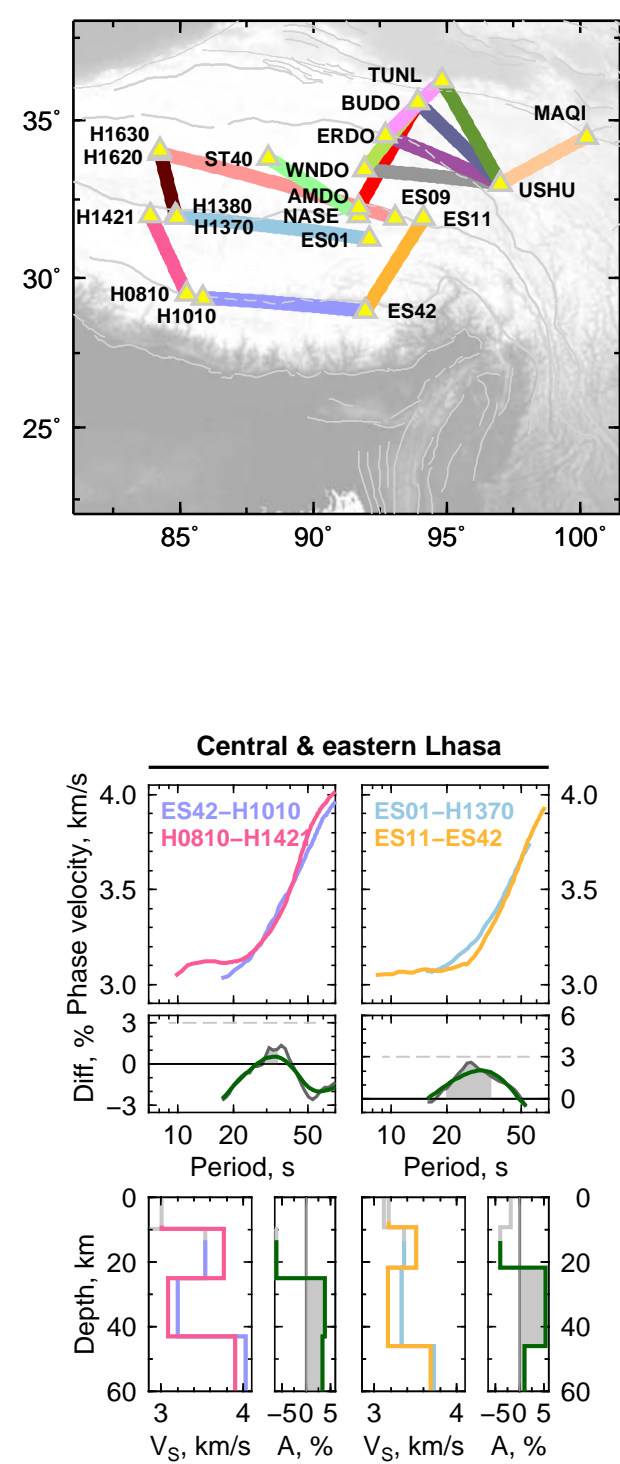

Central Qiangtang

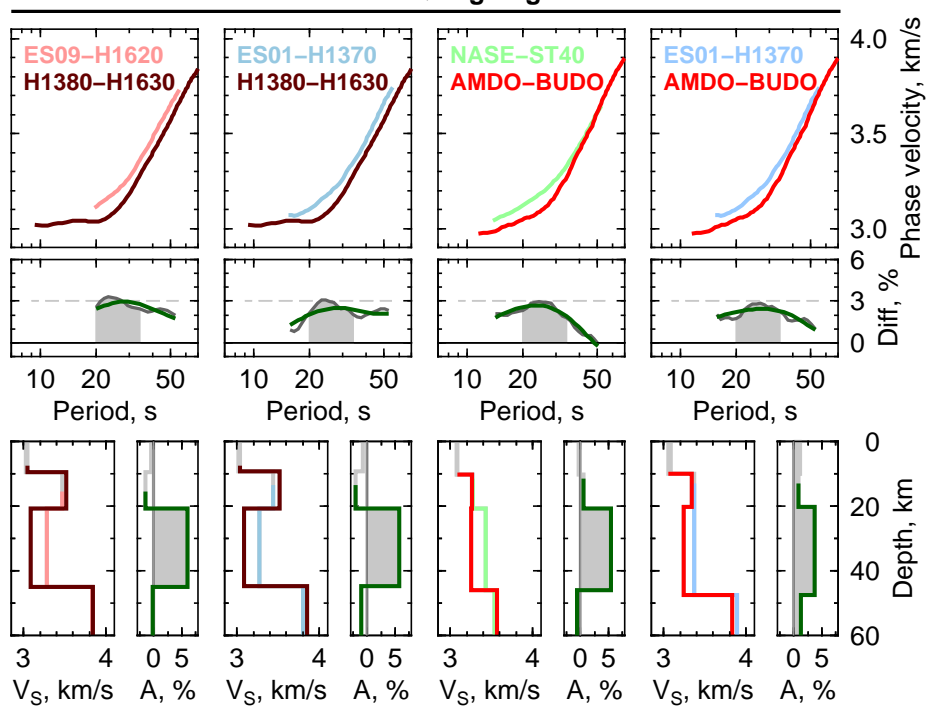

North eastern Tibet

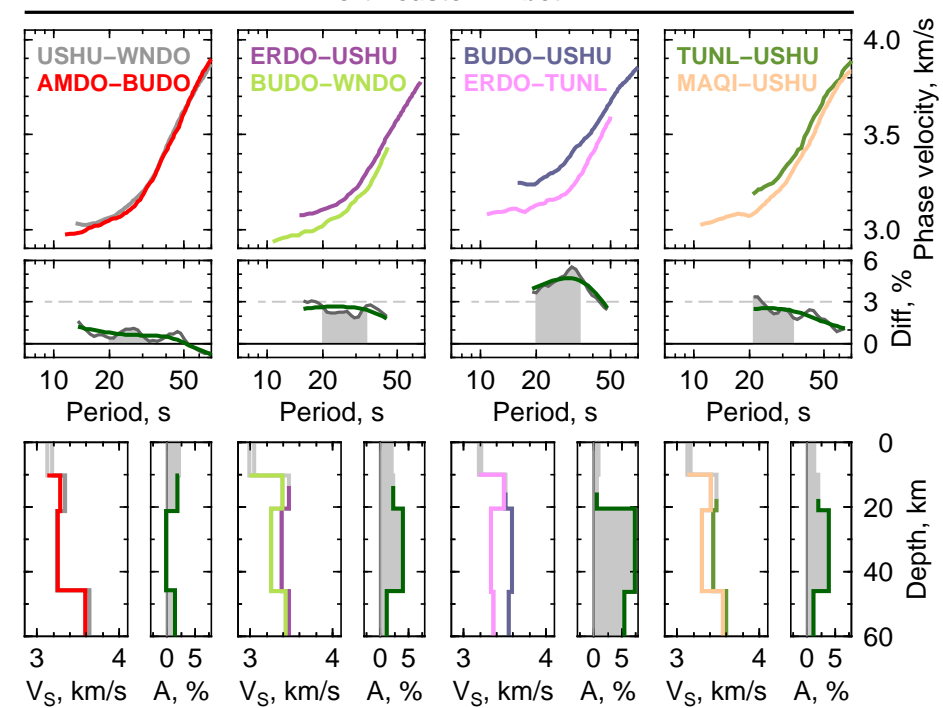

Figure 8. Crustal azimuthal anisotropy beneath central and northeastern Tibet, derived from differential Rayleigh-wave dispersion. Top left: The interstation paths used. Phase-velocity curves and $V_{\mathrm{S}}$ profiles throughout the figure are colour-coded to show correspondence to the paths on the map. The ten sub-columns, grouped by region, each show one pair of phase-velocity curves and their inversion for $V_{\mathrm{S}}$ anisotropy profiles. Top (within each sub-column): Rayleigh-wave phase-velocity curves in the fast- and slow-propagation directions. Middle: The difference between the measured fast and slow phase-velocity curves (dark grey line) and the difference given by best-fitting synthetics (green). Grey shade highlights the phase-velocity difference in the 20-35 s period range, sensitive to the middle and lower crust (Fig. 5). Dashed grey line marks 3 per cent difference. Bottom: Best-fitting 1-D shear-wave speed profiles for each of the phase-velocity curves and corresponding $V_{\mathrm{S}}$ azimuthal anisotropy, from the joint inversion of the two Rayleigh-wave dispersion curves. The 1-D profiles are drawn in colour in the depth ranges well constrained by Rayleigh waves in the period range of this particular dispersion curve (grey outside these depth ranges). Grey shade in the 1-D anisotropy highlights faster propagation along west-east oriented paths. 
The upper mantle: Phase-velocity and shear-velocity azimuthal anisotropy
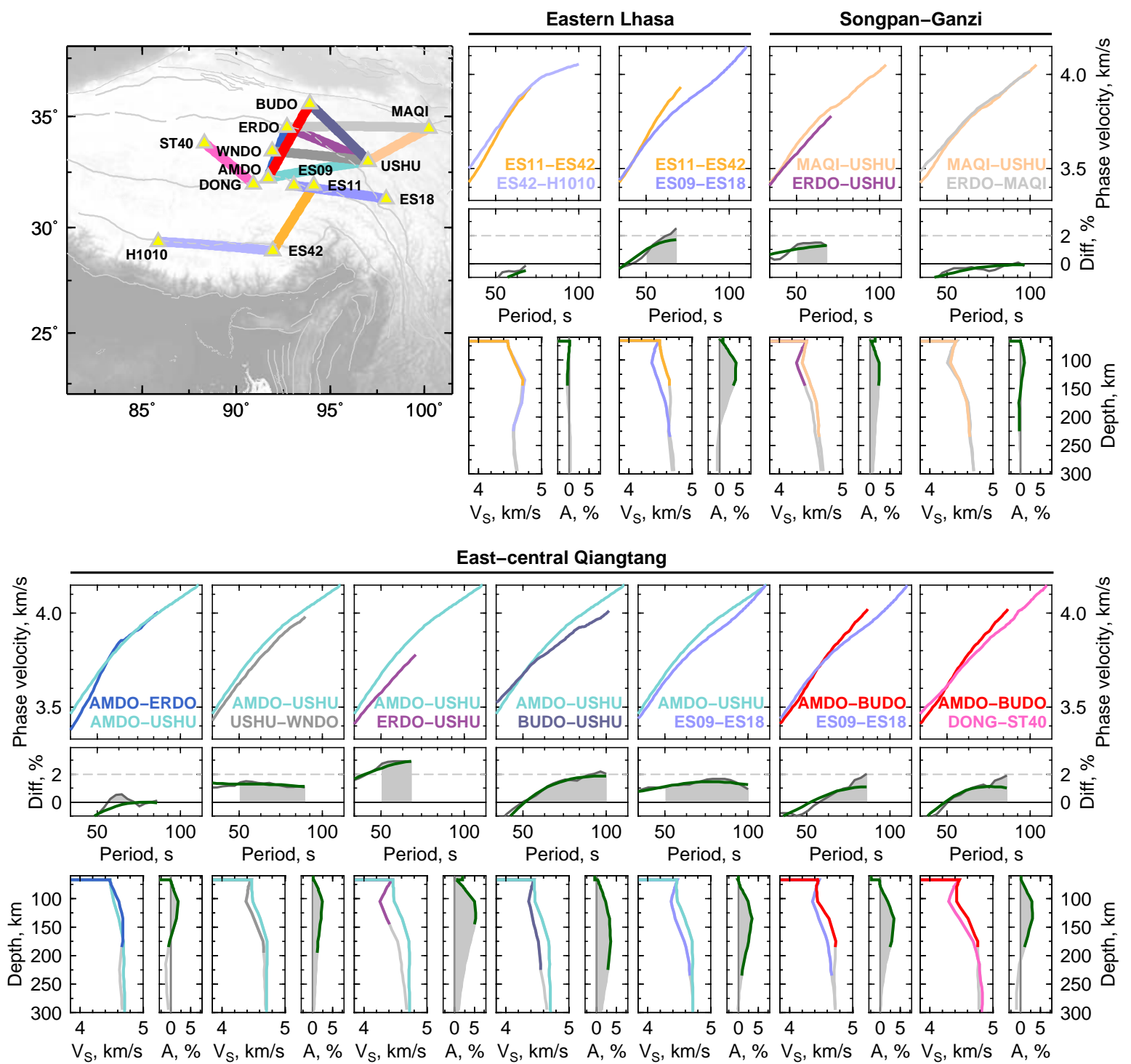

Figure 9. Upper mantle azimuthal anisotropy beneath eastern Tibet, from differential Rayleigh-wave dispersion.

Top left: The interstation paths used. Phase-velocity curves and $V_{\mathrm{S}}$ profiles throughout the figure are colourcoded to show correspondence with the paths on the map. The 11 sub-columns, grouped by region, each show one pair of phase-velocity curves and their inversion for $V_{\mathrm{S}}$ anisotropy profiles. Top (within each sub-column): Rayleigh-wave phase-velocity curves in the fast- and slow-propagation directions. Middle: The difference between the measured fast and slow phase-velocity curves (dark grey line) and the difference given by best-fitting synthetics (green). Grey shade highlights the phase-velocity difference at periods over $50 \mathrm{~s}$, sensitive mainly to the upper mantle (Fig. 5). Dashed grey line marks 2 per cent difference. Bottom: Best-fitting 1-D shear-wave speed profiles for each of the phase-velocity curves and corresponding azimuthal anisotropy, from the joint inversion of the two Rayleigh-wave dispersion curves. The 1-D profiles are drawn in colour in the depth ranges well constrained by Rayleigh waves in the period range of this particular dispersion curve (grey outside these depth ranges). Grey shade in the 1-D anisotropy highlights faster propagation along north-south oriented paths. 


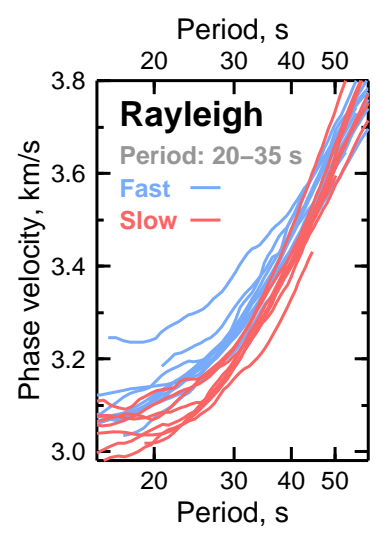

\section{Crust: Strength of azimuthal anisotropy}
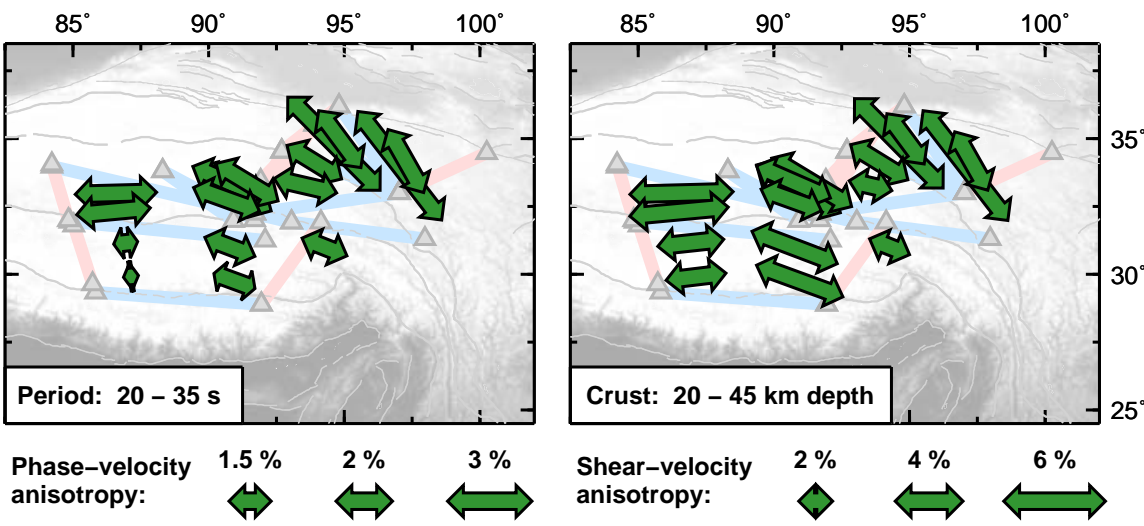

Figure 10. Azimuthal anisotropy in the middle crust. Left: All Rayleigh-wave phase-velocity curves used in the differential dispersion analysis. The curves from "fast" paths are plotted in blue and those from "slow" paths in red (cf. Fig. 8). Centre: Green double-headed arrows indicate the fast-propagation direction and amplitude of anisotropy, measured as the average phase-velocity difference in the 20-35 s period range. Each arrow is plotted along an azimuth that is the average between the azimuths parallel and perpendicular to the azimuths of the faster and slower path of the pair, respectively. In the background, the faster (E-W) and slower (N-S) paths are plotted in pale blue and red, respectively. Right: Fast-propagation directions and amplitudes of shear-wave azimuthal anisotropy in the middle crust ( $\sim 20-45 \mathrm{~km}$ depth), determined in differential dispersion inversions (a joint inversion of each pair of the "fast" and "slow" phase-velocity curves (Fig. 8)). 


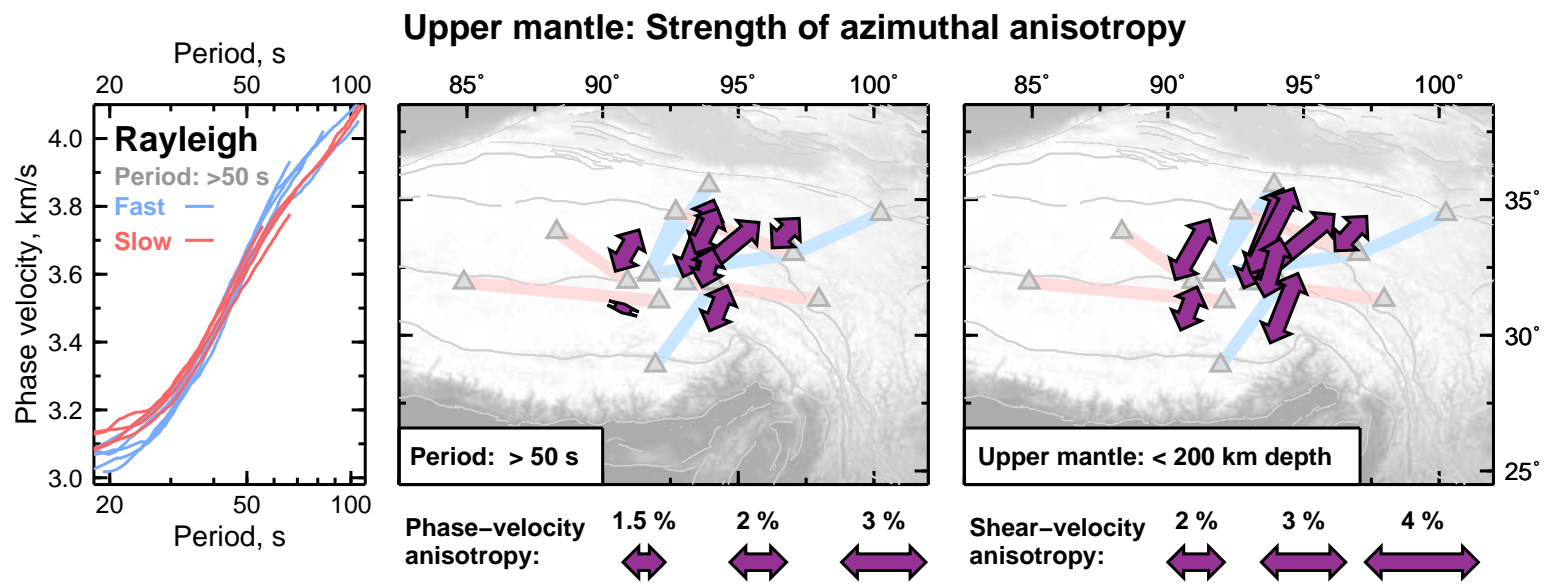

Figure 11. Azimuthal anisotropy in the upper mantle. Left: All Rayleigh-wave phase-velocity curves used in the differential dispersion analysis. The curves from "fast" paths are plotted in blue and those from "slow" paths in red (cf. Fig. 9). Centre: Double-headed arrows indicate the fast-propagation direction and amplitude of anisotropy, measured as the average phase-velocity difference at periods $\geq 50 \mathrm{~s}$. Each arrow is plotted along an azimuth that is the average between the azimuths parallel and perpendicular to the azimuths of the faster and slower path of the pair, respectively. In the background, the faster $(\mathrm{N}-\mathrm{S})$ and slower $(\mathrm{E}-\mathrm{W})$ paths are plotted in pale blue and red, respectively. Right: Fast-propagation directions and amplitudes of shear-wave azimuthal anisotropy in the upper mantle (Moho - $200 \mathrm{~km}$ depth), determined in differential dispersion inversions (a joint inversion of each pair of the "fast" and "slow" phase-velocity curves (Fig. 9)). 


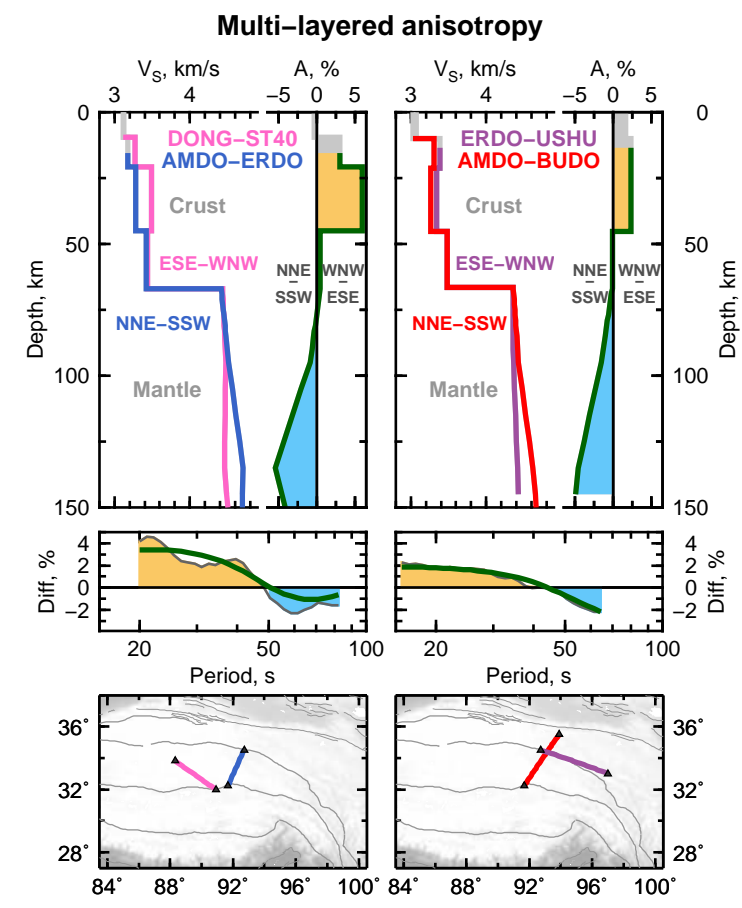

Figure 12. Multi-layered anisotropy beneath east-central Tibet. The models are yielded by the joint inversion of pairs of Rayleigh-wave, phase-velocity curves, from roughly perpendicular interstation paths oriented roughly parallel and perpendicular to the fast-propagation directions in the middle crust and asthenospheric mantle. Map: The location of the paths, colour coded to indicate the 1-D models. Positive and negative anisotropy indicates directions of fast propagation, WNW-ESE and NNE-SSW, respectively. Dark green curve in the middle frames is the synthetic differential dispersion curve. 


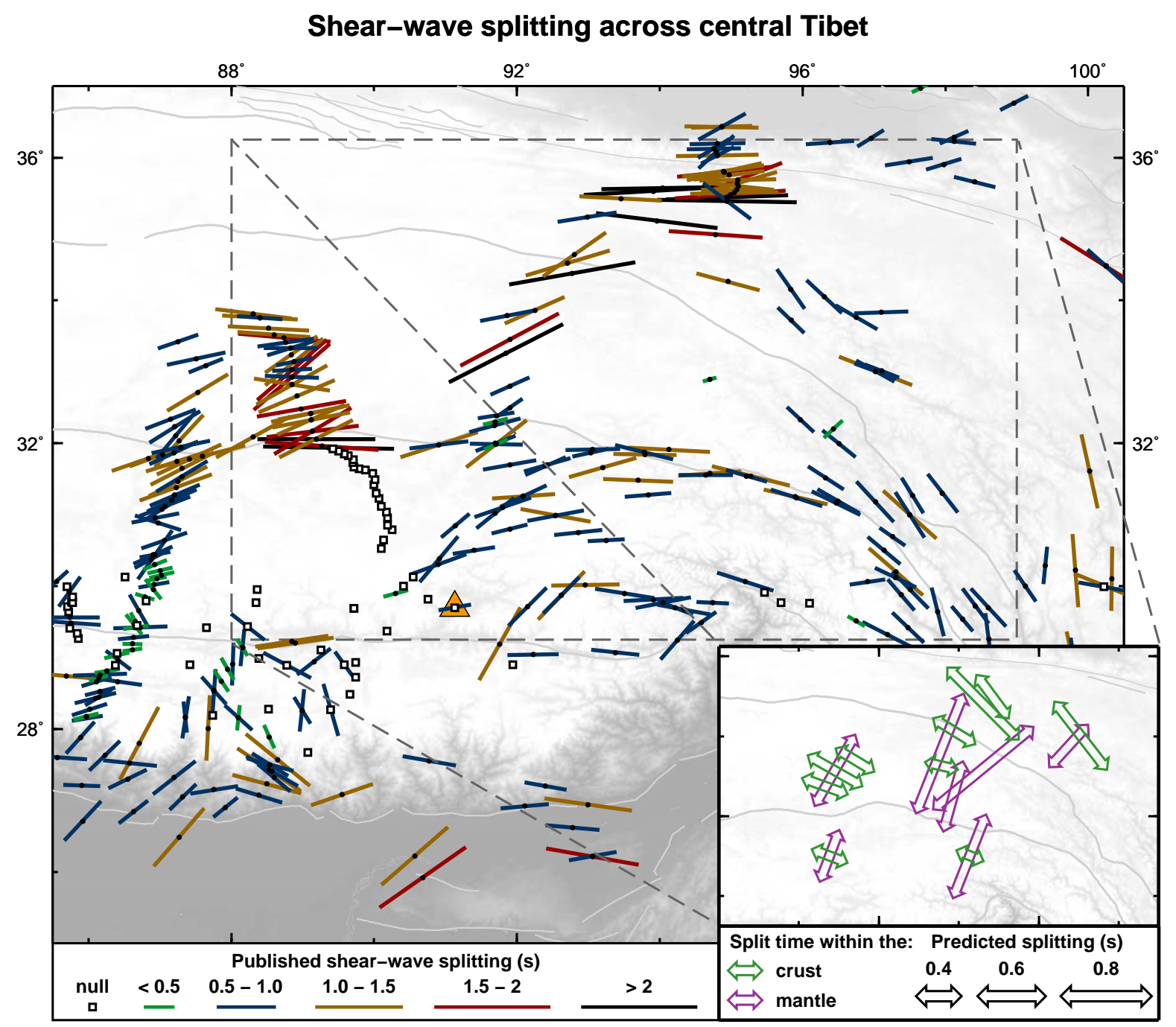

Figure 13. Published shear-wave splitting measurements and the estimated splitting generated within the crust and upper mantle according to our 1-D shear velocity models. Large map: A compilation of $S$-wave splitting estimates as in Fig. 1, with a zoom on central Tibet. Colour-coded length-varying bars indicate the splitting time and fast polarisation direction. Black circles are the locations of seismic stations. Black open squares are stations with null measurements. The orange triangle is the station Lhasa (LSA). Grey dashed rectangle is the location of the inset. Inset: Shear-wave splitting in the crust and upper mantle estimated from our 1-D $S$-velocity models for eastern and central Tibet. Green arrows: Splitting calculated from crustal $S$ velocity and anisotropy (Fig. 8). Purple arrows: Splitting calculated from the upper mantle $S$ velocities and anisotropy ( $<200 \mathrm{~km}$ depth, Fig. 9). The arrows are plotted at locations halfway between the midpoints of the paired interstation paths (see text). 

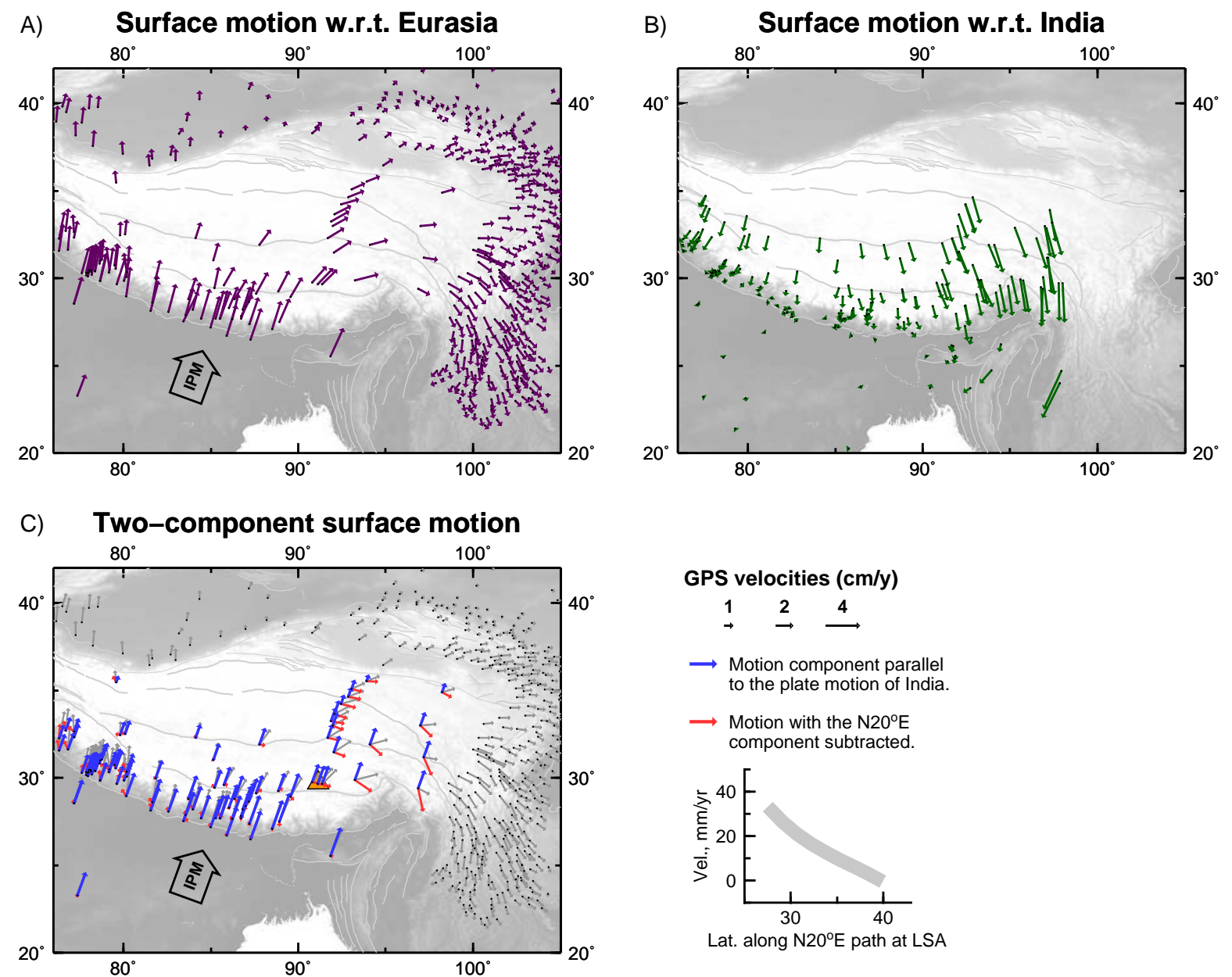

Figure 14. Surface motions across Tibet and surrounding regions from Global Positioning System (GPS) measurements. (a) GPS velocity vectors with respect to stable Eurasia from Zhang et al. (2004). IPM indicates India's plate motion $\left(\sim \mathrm{N} 20^{\circ} \mathrm{E}\right)$. (b) GPS velocity vectors with respect to India from Banerjee et al. (2008). (c) Decomposition of GPS velocity vectors with respect to stable Eurasia into two components. Blue arrows: Velocity parallel to $\sim \mathrm{N} 20^{\circ} \mathrm{E}$, the direction of the Indian-Eurasian collision (Zhang et al. 2004). The velocity at each station is computed while taking into account the slowing of the $\sim \mathrm{N} 20^{\circ} \mathrm{E}$ motion from south to north across Tibet (the grey curve at the bottom right), computed by fitting the data of Zhang et al. (2004) along a profile that passes Lhasa (LSA, orange triangle). Red arrows: The resultant vector following the subtracted $\mathrm{N} 20^{\circ} \mathrm{E}$ velocity component from the original GPS vectors at each station. 


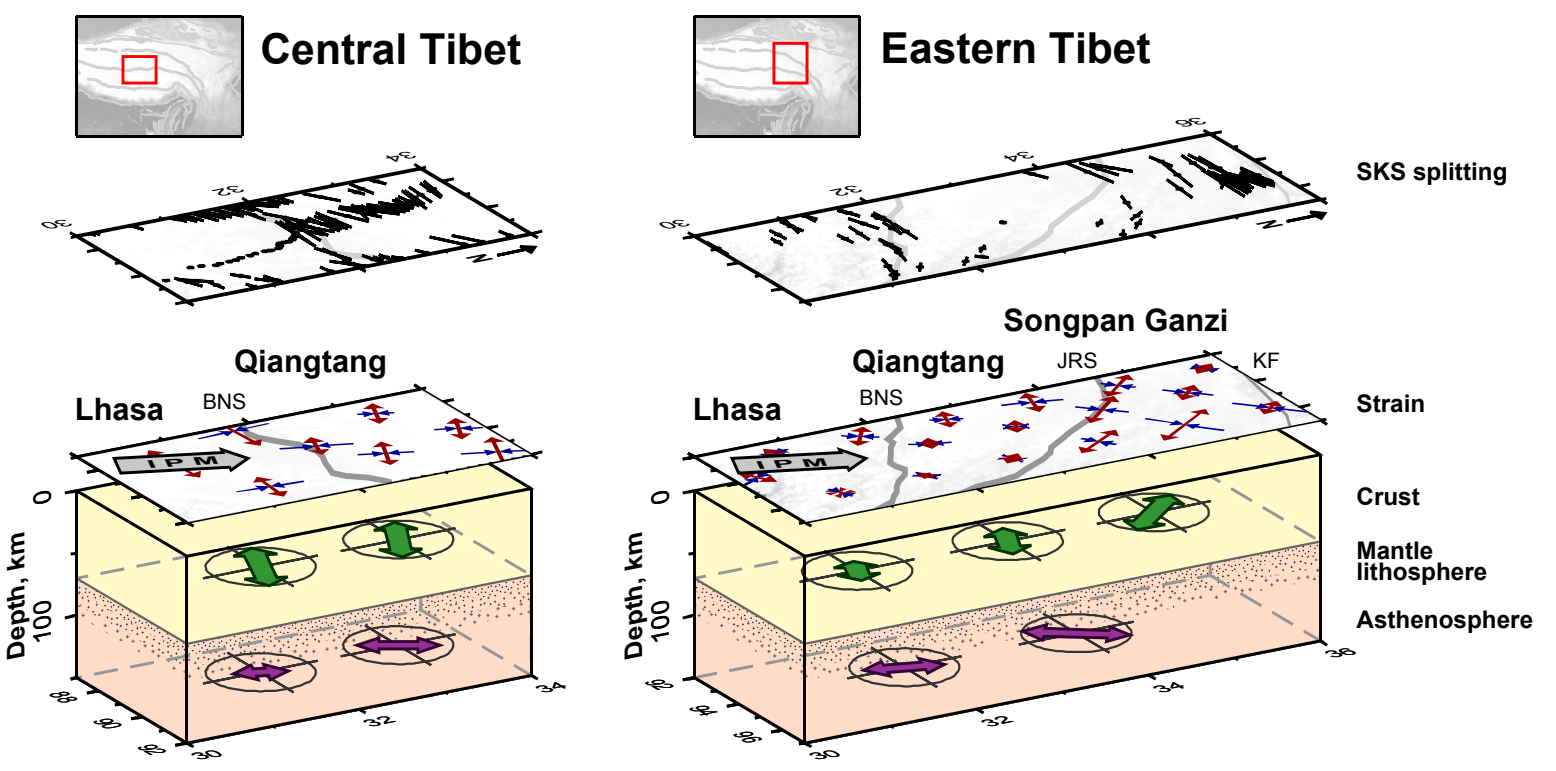

Figure 15. Three-dimensional deformation beneath central and eastern Tibet. Below the maps with shear-wave splitting and the strain at the surface (strain rate principal axes (Kreemer et al. 2003)): blue, compression; red, extension), arrows show azimuthal anisotropy in the Tibetan crust (green) and asthenosphere (purple), averaged from the shear-velocity anisotropy in Figs 10 and 11, respectively. IPM: India's plate motion.
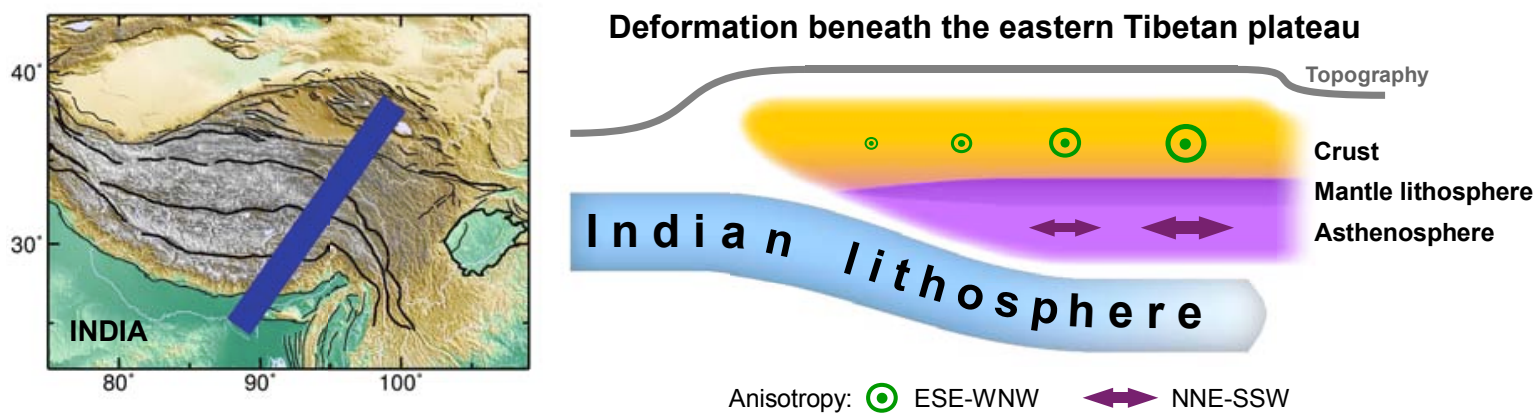

Figure 16. Layering of azimuthal anisotropy beneath eastern Tibet. Subduction of the Indian lithosphere is as mapped by Agius \& Lebedev (2013). 